\title{
ARTíCULO \\ Variabilidad temporal de las masas de agua costeras en bahía San Jorge, Antofagasta, Chile $23^{\circ} \mathrm{S}$ (2008-2012)
}

\author{
Temporal variability of the coastal water masses at San Jorge Bay, \\ Antofagasta, Chile $23^{\circ} \mathrm{S},(2008-2012)$
}

\section{Paola M. Dávila ${ }^{1,3}$ y Jorge Valdés ${ }^{2,3}$}

\begin{abstract}
'Departamento de Ciencias Acuáticas y Ambientales, Facultad de Ciencias del Mar y de Recursos Biológicos, Universidad de Antofagasta, Casilla 170, Antofagasta, Chile.paola.davila@uantof.cl

${ }^{2}$ Laboratorio de Sedimentología y Paleoambientes, Instituto de Ciencias Naturales Alexander von Humboldt, Facultad de Ciencias del Mar y de Recursos Biológicos, Universidad de Antofagasta, Casilla 170, Antofagasta, Chile. jorge.valdes@uantof.cl ${ }^{3}$ Laboratorio Mixto Internacional, 'PALEOTRACES' Institut de Recherche pour le Développement, Universidade Federal Fluminense y Universidad de Antofagasta, Antofagasta, Chile
\end{abstract}

\begin{abstract}
Temporal variability of hydrographic characteristics and coastal water masses are study at San Jorge Bay, northern Chile, with a CTD. The measurements were made along a transect formed by 8 stations maximum, during 8 times at specific days of the 2008-2012 period. Wind characteristics were analyzed for the sample months and 5 day period, including the dates of measurements. The hydrography shows the predominance of 3 modified water masses inside the bay: Subantarctic Surface Water (SASW), Subtropical Surface Water (STSW), and Equatorial Subsurface Water (ESSW). The percentage variability of SASW and STSW depends on the direction of the Chile Coastal Current, which is also modulated by the coastal upwelling favorable wind. This mechanism is responsible of ESSW ascent. This water mass can be introduce to the bay from the north and south sides as it upwells at Punta Angamos and Punta Coloso centers respectively, besides other sites. The dominance of ESSW in the bay's lower layer indicates the entrance of the Subsurface Equatorial Current (SSEC) from the north side and its southern exit. The high percentage of this last water mass during austral winter could be explained by the vertical mixing generated by cooling of the surface layer.
\end{abstract}

Key words: Antofagasta Bay, hydrography, winds, coastal circulation

Resumen.- Se estudia la variabilidad temporal de las características hidrográficas y de las masas de agua de Bahía San Jorge, norte de Chile, en base a mediciones con CTD realizados en una transecta, formada por un máximo de 8 estaciones durante 8 cruceros realizados en días específicos del período 2008-2012. Se analizan las características del viento en los meses de estudio y en períodos de 5 días incluidas las fechas de muestreo. La hidrografía muestra un predominio de 3 masas de agua modificadas: Agua Superficial Subantártica (ASSA), Agua Superficial Subtropical (ASST) y Agua Ecuatorial Subsuperficial (AESS). La variación de los porcentajes de las masas de agua superficiales (ASSA y ASST) dependería fundamentalmente de las características de la dirección de la Corriente Costera de Chile la cual estaría modula por el viento favorable a la surgencia costera que a su vez sería responsable de los aportes de AESS a la superficie. Esta última masa de agua podría estar ingresando tanto por el sector norte como por el sur de la bahía, al provenir de los focos de surgencia de Punta Angamos y Punta Coloso (entre otros focos), respectivamente. Por otra parte, el predominio de AESS en la capa inferior de la bahía, estaría indicando el ingreso de la Corriente Ecuatorial Subsuperficial (CESS) desde el norte y su vaciamiento por el sur. A su vez, los altos porcentajes de esta masa de agua en invierno podrían deberse a efectos de mezcla vertical generados por un enfriamiento, de la capa superficial, típico de invierno.

Palabras clave: Bahía de Antofagasta, hidrografía, vientos, circulación costera

\section{INTRODUCCIÓN}

Las zonas costeras constituyen ambientes heterogéneos debido a que sus aguas se ven afectadas por una gran cantidad de procesos que afectan su variabilidad, como el efecto de las interacciones con la atmósfera (radicación solar, enfriamiento, precipitaciones y viento), procesos oceanográficos (surgencia costera y mezcla) y/o interacciones con el continente (drenaje de agua dulce)
(Bourke \& Pattullo 1974, Marghany 2012). Los estudios sobre las características de las masas de agua en zonas costeras son escasos en relación con aquellos de las zonas oceánicas (Emery \& Meincke 1986, Tomczak 1999). El estudio básico de las masas de agua se realiza a través de los diagramas T_S, es decir a través de sus propiedades conservativas, pero se identifican con mayor precisión si 
se le agregan sus propiedades no conservativas, como el contenido de oxígeno disuelto y/o nutrientes (Tomczak 1999). Las masas de agua se caracterizan por cumplir un ciclo de vida en los océanos, se originan en un lugar específico, luego durante su transporte por las corrientes oceánicas y/o costeras, se ven afectadas por procesos de mezcla que modifican sus propiedades originales hasta hacerlas desaparecer casi por completo, etapa conocida como envejecimiento o decaimiento (Tomczak 1999).

La Bahía San Jorge (BSJ), también conocida como Bahía de Antofagasta pertenece al sistema de bahías de la Península de Mejillones, norte de Chile. Es una bahía semicerrada con una boca abierta hacia el sur y una profundidad que alcanza los 160-190 m en la boca (Fig. 1) (Escribano \& Hidalgo 2001, Escribano et al. 2002). Debido a su configuración, la bahía está expuesta a vientos provenientes del sur y suroeste generados por el Anticiclón del Pacífico Sur Oriental (Saavedra \& Foppiano 1992, Strub et al. 1998), de manera tal que el viento es uno de las forzantes principales de su circulación (Escribano \& Hidalgo 2001). Escribano et al. (2002) y Piñones et al. (2007) establecen que la BSJ se encuentra afectada por los procesos de surgencia costera que ocurren en el sector sur de la bahía, específicamente frente a Punta Coloso (Fig. 1), Punta Jorgillo y el Cobre (estos dos últimos sitos ubicados al sur de Punta Coloso). Por otra parte, sus aguas interiores se caracterizan por presentar registros de temperatura entre 2 a $3^{\circ} \mathrm{C}$ superiores a las aguas del sector externo a la bahía (Piñones et al. 2007). Esto último sugiere que las aguas de la BSJ son retenidas a través de un giro ciclónico (Escribano \& Hidalgo 2001, Piñones et al. 2007), favoreciendo un incremento de la temperatura debido a la alta radiación solar característica de estas latitudes (Stewart 2003), y a una mayor fluctuación diaria de este parámetro (Kaplan et al. 2003). Por otro lado, la dinámica del sistema de Corrientes de Humboldt, en especial la variabilidad temporal y espacial de la Contracorriente Perú-Chile (CCPCh), y de la Corriente Ecuatorial Subsuperficial (CESS), de dirección sur y en particular de la Corriente Costera de Chile (CCCh) de dirección reversible, frente a la Península de Mejillones (Strub et al. 1998), tendría influencia en el patrón de circulación de la bahía (Escribano \& Hidalgo 2001). Dado que las zonas costeras son heterogéneas resulta necesario poder determinar la variabilidad espacio temporal de sus masas de agua.

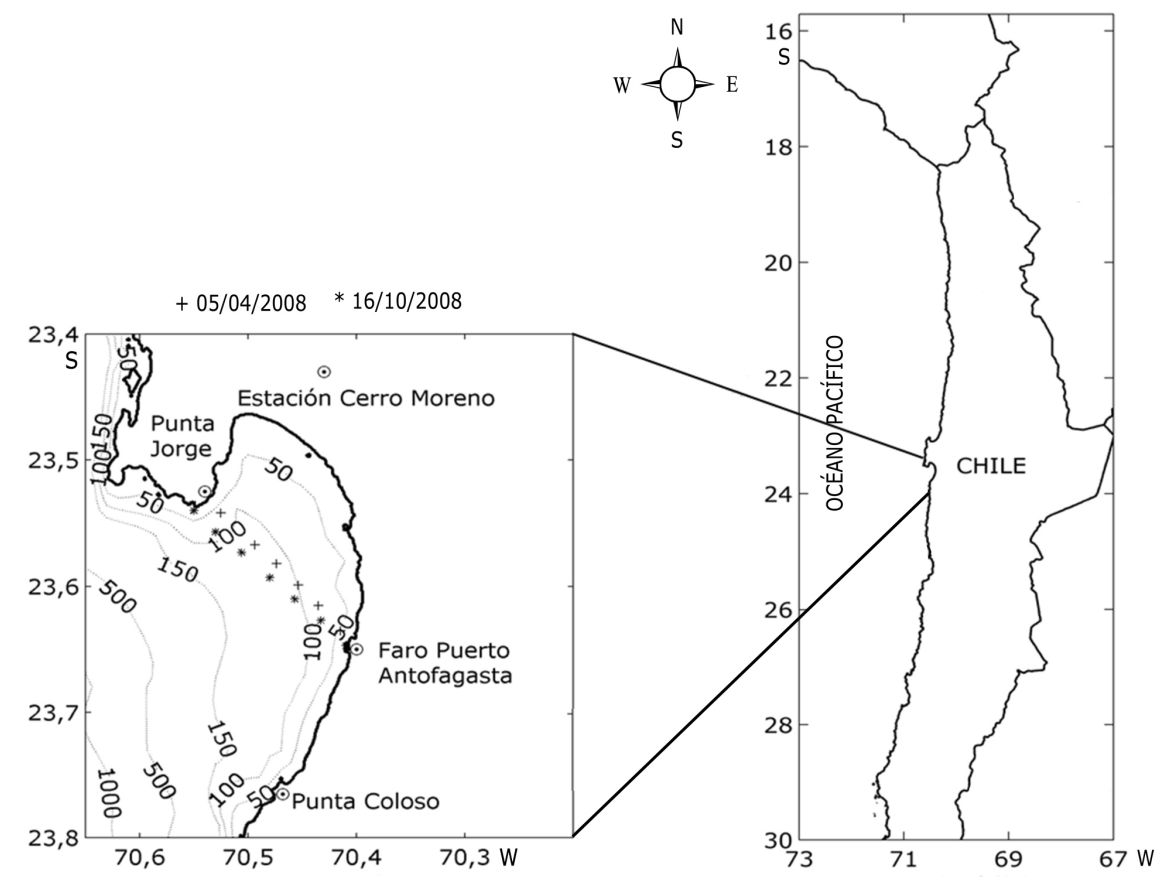

Figura 1. Área de estudio y batimetría de la BSJ, posición de las estaciones oceanográficas asociadas a las mediciones de datos de CTD del 5 de abril 2008, y de aquellas asociadas a las mediciones de CTD de las restantes ocasiones de estudio, por ejemplo 16 octubre 2008 / Study area and bathymetry of Bahía San Jorge, Positions of the oceanographic stations for CTD data during 5 April 2008 and for those associated with CTD at the other study occasions, for example 16 October 2008 
El presente estudio tiene por objeto describir la variabilidad temporal de las características hidrográficas y de las masas de agua de la bahía San Jorge para el período 2008-2012 en función de los procesos físicos (dinámica del sistema de corrientes, surgencia costera, mezcla vertical y estratificación) que se manifiestan en distintas escalas espacio temporales propias de esta zona de estudio.

\section{Materiales Y MÉTODOS}

Se realizaron 8 cruceros hidrográficos en la BSJ durante el período 2008-2012, en los cuales se realizaron mediciones de variables físico-químicas en un máximo de 8 estaciones localizadas sobre una transecta comprendida entre el faro del Puerto de Antofagasta y Punta Jorge situada en la Península de Mejillones (Fig. 1). Esto se realizó durante diversas épocas del año dentro del período de estudio (Tabla 1). Las variables hidrográficas de temperatura, y salinidad se obtuvieron con CTD SeaBird SBE-19 plus. Problemas puntuales en el registro de datos del CTD o registros de poca extensión en profundidad, explican el número cambiante de estaciones utilizadas para el análisis de masas de agua en los diferentes cruceros. Cabe agregar que en los últimos 3 cruceros (Tabla 1), también se midió el contenido de oxígeno disuelto con un CTDO SeaBird SBE-19 plus. Las mediciones con CTD se realizaron hasta los $90 \mathrm{~m}$ aproximadamente en la zona central de la bahía, sin embargo en las mediciones del 6 de abril de 2010 los datos se registraron hasta un máximo de $70 \mathrm{~m}$ de profundidad aproximadamente. La estructura hidrográfica fue establecida a través de secciones transversales de temperatura, salinidad y sigma-t (Figs. 2-3, 4-5 y 6-7); la composición de las masas de agua presentes al interior de la bahía se identificó mediante

Tabla 1. Número de transecta, fecha de medición, variables hidrográficas medidas con CTD, número de perfiles considerados en el análisis de masas de agua / Transect number, dates measurement, hydrography variable measured with CTD, number of profiles considered in the water mass analysis

\begin{tabular}{lclc}
\hline N & Fecha & \multicolumn{1}{c}{ Variables Hidrográficas } & $\begin{array}{c}\text { No Perfiles } \\
\text { considerados }\end{array}$ \\
\hline I & $05 / 04 / 2008$ & CTD-SBE-19 plus (T,S,P) & 7 \\
II & $16 / 10 / 2008$ & CTD-SBE-19 plus (T,S,P) & 6 \\
III & $27 / 03 / 2009$ & CTD-SBE-19 plus (T,S,P) & 7 \\
IV & $28 / 08 / 2009$ & CTD-SBE-19 plus (T,S,P) & 7 \\
V & $06 / 04 / 2010$ & CTD-SBE-19 plus (T,S,P) & 7 \\
VI & $10 / 08 / 2010$ & CTD-SBE-19 plus (T,S,P,O,$F)$ & 7 \\
VII & $25 / 03 / 2011$ & CTD-SBE-19 plus (T,S,P,O, F) & 8 \\
VIII & 22,27 y & CTD-SBE-19 plus (T,S, P,O, F) & 5 \\
& $29 / 06 / 2012$ & & \\
\hline
\end{tabular}

diagramas T-S (Figs. 8 y 9) y esquemas de temperatura y salinidad versus contenido de oxígeno disuelto (Fig. 10). Estos últimos esquemas sólo se realizaron para los 3 muestreos finales. También se calculó la distribución vertical del porcentaje de masas de agua (Figs. 11 y 12) de acuerdo a las siguientes ecuaciones (Mamayev 1975):

$$
\begin{aligned}
& T=m_{1} T_{1}+m_{2} T_{2}+m_{3} T_{3} \\
& S=m_{1} S_{1}+m_{2} S_{2}+m_{3} S_{3} \\
& 1=m_{1}+m_{2}+m_{3}
\end{aligned}
$$

donde los pares $\mathrm{T}_{1}-\mathrm{S}_{1}, \mathrm{~T}_{2}-\mathrm{S}_{2}$ y $\mathrm{T}_{3}-\mathrm{S}_{3}$ representan los índices termohalinos de las 3 masas de agua consideradas en este trabajo. Las variables $\mathrm{m}_{1}, \mathrm{~m}_{2} \mathrm{y} \mathrm{m}_{3}$ representan las proporciones de cada una de las masas de agua que se desea calcular, y por lo tanto las incógnitas del sistema de ecuaciones. Finalmente, T y S corresponden al valor de temperatura y salinidad, respectivamente, de cada perfil analizado y sometido al cálculo de las proporciones de las masas de agua. Cabe destacar que la suma de las 3 proporciones del porcentaje de masas de agua tiene que ser igual a 1 o al $100 \%$. Los cálculos se realizaron con un programa computacional propio, resolviendo el sistema de ecuaciones (1) de manera matricial. En efecto, para dicho cálculo se consideraron los índices termohalinos para el Agua Superficial Subtropical (ASST) $\left(20^{\circ} \mathrm{C} ; 35,3\right)$, el Agua Superficial Subantártica (ASSA) $\left(15^{\circ} \mathrm{C} ; 34,2\right)$ y el Agua Ecuatorial Subsuperficial (AESS) $\left(10^{\circ} \mathrm{C} ; 34,7\right)$. Dichos índices están dentro de cada uno de los rangos de temperatura y salinidad que definen a las masas de agua según Sobarzo \& Figueroa (2001) (Figs. 8 y 9), es decir para el ASST $\left(16-24^{\circ} \mathrm{C}\right.$ y $\left.34,9-35,3\right)$, ASSA $\left(9-15^{\circ} \mathrm{C}\right.$ y $33-$ $34,3)$ y $\operatorname{AESS}\left(8-12^{\circ} \mathrm{C}\right.$ y $\left.34,4-34,9\right)$. Adicionalmente, se determinó el espesor de la capa de mezcla y capa estratificada, mediante los valores límites del gradiente vertical de temperatura (Tabla 2). En efecto, la capa de mezcla se determinó entre la superficie y la profundidad en la cual el gradiente vertical de temperatura alcanzó un valor igual o menor a $0,1^{\circ} \mathrm{C} \mathrm{m}^{-1}$, mientras que la capa estratificada corresponde al grosor de la capa entre la superficie o la base de capa de mezcla y la profundidad donde el gradiente vertical de temperatura es mayor a $0,1^{\circ} \mathrm{C} \mathrm{m}^{-1}$, es decir hasta la profundidad a partir de la cual el gradiente vertical de temperatura comienza a disminuir en forma consecutiva por debajo de dicho valor dando lugar a la capa profunda de la columna de agua. El uso de gradientes verticales de temperatura como valores límites entre las capas de mezcla y estratificada, se debe a que la distribución de la densidad está determinada, en esta zona de estudio, principalmente por la distribución de la 
Tabla 2. Estadística básica para el grosor de la capa de mezcla y estratificada, parámetro de estratificación (Phi) y profundidad de las estaciones oceanográficas / Basic statistics for the width of the mixed and stratified layer, stratification parameter (Phi), and depth of the oceanographic stations

\begin{tabular}{|c|c|c|c|c|c|c|}
\hline $\begin{array}{c}\mathrm{N}^{\circ} \\
\text { Transecta }\end{array}$ & $\begin{array}{l}\text { Fecha de } \\
\text { muestreo }\end{array}$ & $\begin{array}{c}\mathrm{N}^{\circ} \text { de } \\
\text { estaciones } \\
\text { consideradas }\end{array}$ & $\begin{array}{c}\mathrm{D}_{\text {mezcla }}(\mathrm{m}) \\
\mathrm{H}_{\text {est. }}(\mathrm{m}) \\
\operatorname{Phi}\left(\mathrm{J} \mathrm{m}^{-3}\right) \\
\mathrm{Z}(\mathrm{m})\end{array}$ & $\begin{array}{c}\mathrm{D}_{\text {d. est }}(\mathrm{m}) \\
\mathrm{H}_{\text {d. est }}(\mathrm{m}) \\
\mathrm{Phi}_{\text {d.std }}\left(\mathrm{J} \mathrm{m}^{-3}\right) \\
\mathrm{Z}_{\text {d. std }}(\mathrm{m})\end{array}$ & $\begin{array}{c}\mathrm{D}_{\max }(\mathrm{m}) \\
\mathrm{H}_{\max }(\mathrm{m}) \\
\mathrm{Phi}_{\max }\left(\mathrm{J} \mathrm{m}^{-3}\right) \\
\mathrm{Z}_{\max }(\mathrm{m})\end{array}$ & $\begin{array}{c}\mathrm{D}_{\min }(\mathrm{m}) \\
\mathrm{H}_{\min }(\mathrm{m}) \\
\mathrm{Phi}_{\min }\left(\mathrm{J} \mathrm{m}^{-3}\right) \\
\mathrm{Z}_{\min }(\mathrm{m})\end{array}$ \\
\hline I & $05 / 04 / 2008$ & 7 & $\begin{array}{c}0 \\
10 \\
59,74 \\
85,28\end{array}$ & $\begin{array}{l} \pm 0 \\
\pm 3,11 \\
\pm 12,80 \\
\pm 22,82\end{array}$ & $\begin{array}{c}0 \\
15 \\
69,27 \\
106\end{array}$ & $\begin{array}{c}0 \\
5 \\
32,07 \\
42\end{array}$ \\
\hline II & $16 / 10 / 2008$ & 6 & $\begin{array}{c}2,5 \\
8,5 \\
40,03 \\
70,83\end{array}$ & $\begin{array}{l} \pm 1,38 \\
\pm 3,94 \\
\pm 21,86 \\
\pm 40,17\end{array}$ & $\begin{array}{c}4 \\
14 \\
63,58 \\
97\end{array}$ & $\begin{array}{c}0 \\
3 \\
12,43 \\
17\end{array}$ \\
\hline III & $27 / 03 / 2009$ & 7 & $\begin{array}{c}0,28 \\
13,28 \\
70,96 \\
76,28\end{array}$ & $\begin{array}{l} \pm 0,75 \\
\pm 4,34 \\
\pm 24,70 \\
\pm 29,37\end{array}$ & $\begin{array}{c}2 \\
19 \\
98,34 \\
95\end{array}$ & $\begin{array}{c}0 \\
7 \\
29,67 \\
29\end{array}$ \\
\hline IV & $28 / 08 / 2009$ & 7 & $\begin{array}{c}2,14 \\
4,71 \\
42,74 \\
73\end{array}$ & $\begin{array}{l} \pm 1,57 \\
\pm 3,59 \\
\pm 16,75 \\
\pm 25,79\end{array}$ & $\begin{array}{c}4 \\
12 \\
57,02 \\
93\end{array}$ & $\begin{array}{c}0 \\
1 \\
7,57 \\
21\end{array}$ \\
\hline V & $06 / 04 / 2010$ & 7 & $\begin{array}{c}2,14 \\
10,85 \\
49,99 \\
60\end{array}$ & $\begin{array}{l} \pm 1,57 \\
\pm 4,09 \\
\pm 14,47 \\
\pm 14,47\end{array}$ & $\begin{array}{c}5 \\
15 \\
73,99 \\
79\end{array}$ & $\begin{array}{c}0 \\
5 \\
26,82 \\
25\end{array}$ \\
\hline VI & $10 / 08 / 2010$ & 7 & $\begin{array}{c}6,85 \\
1,57 \\
13,81 \\
61,14\end{array}$ & $\begin{array}{l} \pm 6,49 \\
\pm 1,40 \\
\pm 8,79 \\
\pm 27,56\end{array}$ & $\begin{array}{c}18 \\
4 \\
22,80 \\
84\end{array}$ & $\begin{array}{c}0 \\
0 \\
0,09 \\
12\end{array}$ \\
\hline VII & $25 / 03 / 2011$ & 8 & $\begin{array}{c}0 \\
12,75 \\
55,44 \\
83,12\end{array}$ & $\begin{array}{l} \pm 0 \\
\pm 2,65 \\
\pm 24,57 \\
\pm 33,53\end{array}$ & $\begin{array}{c}0 \\
17 \\
90,96 \\
116\end{array}$ & $\begin{array}{c}0 \\
10 \\
23,77 \\
31\end{array}$ \\
\hline VIII & $\begin{array}{l}22,27 \mathrm{y} \\
28 / 06 / 2012\end{array}$ & 5 & $\begin{array}{c}8,2 \\
6,6 \\
36,44 \\
90,20\end{array}$ & $\begin{array}{l} \pm 3,96 \\
\pm 3,36 \\
\pm 27,02 \\
\pm 13,03\end{array}$ & $\begin{array}{c}15 \\
11 \\
64,89 \\
104\end{array}$ & $\begin{array}{c}5 \\
2 \\
33,90 \\
69\end{array}$ \\
\hline
\end{tabular}

temperatura, ejerciendo la salinidad un efecto menor sobre la densidad. Se calculó también la profundidad media de los perfiles analizados en cada fecha de muestreo y el grado de estratificación de la columna de agua (Tabla 2) a través del índice de estratificación de Simpson \& Hunter (1974) utilizado aquí como parámetro de estratificación $\Phi_{\mathrm{s}}$ (ecuación 2) (Hidalgo-González \& Álvarez-Borgoño 2008). El parámetro $\Phi_{\mathrm{s}}$ representa la cantidad de energía mecánica requerida para llevar a cabo la mezcla vertical, la cual tiene unidades de Joule por metro cúbico $\left(\mathrm{J} \mathrm{m}^{-3}\right)$. El rango de este parámetro varía entre 0 y un valor positivo, indicando una capa bien mezclada y una capa con cierto grado de estratificación, respectivamente. A medida que el valor de $\Phi_{\mathrm{s}}$ se incrementa, mayor es la energía requerida para romper la estratificación. El valor de $\Phi_{\mathrm{s}}$ se obtiene de la ecuación (2): 


$$
\emptyset_{s}=\left(\frac{1}{k}\right) \sum_{k}^{0}(\rho-\bar{\rho}) g Z \Delta Z
$$

donde $\mathrm{k}(\mathrm{m})$ representa la profundidad de integración de la columna de agua; $\mathrm{Z}(\mathrm{m})$ la coordenada vertical; $\rho$ y $\bar{\rho}$, la densidad y densidad media de la columna de agua, ambas en $\mathrm{kg} \mathrm{m}^{-3} ; g$ la aceleración de la gravedad $\left(\mathrm{m} \mathrm{s}^{-2}\right)$; y $\Delta Z$ el intervalo de profundidad entre 2 niveles consecutivos. En este trabajo se adoptó un intervalo de profundidad de $1 \mathrm{~m}$.

Se analizaron imágenes de TSM del sensor MODIS (Moderate Resolution Imaging Spectroradiometer) correspondiente al satélite AQUA de la NASA, las cuales tienen $1,1 \mathrm{~km}$ de resolución espacial, en el sector que incluye a la península de Mejillones y sistema de bahías asociadas $\left(22-24,5^{\circ} \mathrm{S}\right.$ y $\left.70-72^{\circ} \mathrm{W}\right)$ (Fig. 13). Esto con el fin de comparar mediciones de temperaturas superficiales in situ y remotas, además de visualizar posibles procesos de surgencia en los focos de ocurrencia característicos, solo en períodos de verano y/o cuando se encontraron imágenes disponibles. Se muestra un ejemplo de imágenes de TSM consecutivas obtenidas en marzo 2009. Los datos de dichas imágenes fueron reprocesadas por la NASA en mayo 2012.

Así mismo, se analizaron las características del viento para cada uno de los meses de muestreo con el fin de identificar posibles procesos de surgencia (Tablas 3 y 4), como así también en un período de 5 días incluyendo las fechas de muestreo (Tabla 5). Se calculó la componente zonal y meridional promedio horaria de un ciclo de $24 \mathrm{~h}$, utilizando los valores horarios de viento para cada mes de muestreo (promedio horario mensual), de acuerdo a las ecuaciones (3) lo que permitió identificar el período del día en el que la velocidad de la componente meridional fue mayor o igual a $5 \mathrm{~m} \mathrm{~s}^{-1}$. Esto último también se analizó en las fechas de muestreo (Tabla 4). Adicionalmente, se realizó un análisis de la frecuencia de la dirección de los vientos, que incluye porcentajes de calma, porcentajes de dirección variable y porcentajes de horas sin información, en cada mes de muestreo (Tabla 3). Un análisis similar se realizó para períodos de 5 días, incluyendo las fechas de muestreo (Tabla 5). Las componentes zonal y meridional del viento se calcularon de acuerdo a las siguientes ecuaciones:

$$
\begin{aligned}
& u_{w}=-|\vec{w}| \sin \varphi \\
& v_{w}=-|\vec{w}| \cos \varphi
\end{aligned}
$$

donde, $u_{w} \mathrm{y} v_{w}$ representan las componentes zonal y meridional del viento, respectivamente. Mientras que $|W|$ representa el módulo de intensidad del viento en $\mathrm{m} \mathrm{s}^{-1}$ y $\varphi$ representa la dirección de donde viene el viento en grados. En todos los casos se utilizó el registro de viento horario (intensidad y dirección) de la estación meteorológica ubicada en el aeropuerto de Cerro Moreno, localizado en

Tabla 3. Distribución porcentual de la dirección del viento, para los meses de muestreo hidrográfico (NE noreste; E este; SE sureste, $\mathrm{S}$ sur, SW suroeste, $\mathrm{W}$ oeste, $\mathrm{NW}$ noroeste, $\mathrm{N}$ norte, $\mathrm{C}$ calma, $\mathrm{V}$ viento variable, S/D sin datos) / Porcentual wind direction distribution, for the months of hydrographic measurements (NE Northeast; E east; SE southeast; S south; SW south west; W west; NW northwest; $\mathrm{N}$ north; $\mathrm{C}$ calm; $\mathrm{V}$ variable wind; S/D without data)

\begin{tabular}{lccccccccccc}
\hline & $\begin{array}{c}\mathrm{NE} \\
\%\end{array}$ & $\begin{array}{c}\mathrm{E} \\
\%\end{array}$ & $\begin{array}{c}\mathrm{SE} \\
\%\end{array}$ & $\begin{array}{c}\mathrm{S} \\
\%\end{array}$ & $\begin{array}{c}\mathrm{SW} \\
\%\end{array}$ & $\begin{array}{c}\mathrm{W} \\
\%\end{array}$ & $\begin{array}{c}\mathrm{NW} \\
\%\end{array}$ & $\begin{array}{r}\mathrm{N} \\
\%\end{array}$ & $\begin{array}{c}\mathrm{C} \\
\%\end{array}$ & $\begin{array}{c}\mathrm{V} \\
\%\end{array}$ & $\begin{array}{c}\mathrm{S} / \mathrm{D} \\
\%\end{array}$ \\
\hline Abril 2008 & 1,52 & 3,47 & 3,88 & 51,25 & 13,89 & 0,55 & 0,97 & 0,42 & 14,86 & 8,89 & 0,27 \\
Octubre 2008 & 0,40 & 0,94 & 0,27 & 46,24 & 32,93 & 4,70 & 3,36 & 4,03 & 1,88 & 5,24 & 0 \\
Marzo 2009 & 0,94 & 2,82 & 2,95 & 56,45 & 11,42 & 0,54 & 0,54 & 0,94 & 12,63 & 10,75 & 0,13 \\
Agosto 2009 & 2,28 & 1,34 & 2,01 & 47,98 & 14,92 & 1,34 & 3,76 & 10,62 & 10,61 & 5,10 & 0 \\
Abril 2010 & 1,38 & 1,53 & 2,77 & 60,13 & 13,33 & 0,97 & 0,97 & 4,16 & 5,97 & 8,75 & 0 \\
Agosto 2010 & 1,67 & 2,15 & 3,09 & 55,60 & 8,47 & 4,84 & 7,79 & 10,21 & 1,88 & 4,83 & 0 \\
Marzo 2011 & 3,36 & 9,81 & 6,76 & 57,93 & 4,70 & 0,27 & 0,67 & 2,64 & 2,06 & 11,82 & 0 \\
Junio 2012 & 4,86 & 2,64 & 4,72 & 62,92 & 5,83 & 3,61 & 3,75 & 8,47 & 2,36 & 0,42 & 0 \\
\hline
\end{tabular}


Tabla 4. Características del viento para cada mes y día de medición de los períodos de estudio. Porcentaje de la velocidad de la componente meridional del viento $\left(W_{v}\right) \geq 5 \mathrm{~m} \mathrm{~s}^{-1}$ e intervalo de duración promedio mensual donde la componente meridional del viento alcanza intensidades mayores a dicho valor crítico / Wind characteristics for each month and day of measurement. Wind meridional component velocity percentage $\left(W_{v}\right) \geq 5 \mathrm{~m} \mathrm{~s}^{-1}$ and mean seasonal interval duration where the north-south wind component reaches intensities higher than the critical value

\begin{tabular}{|c|c|c|c|c|c|c|}
\hline Mes & Año & $\begin{aligned} & \% \mathrm{~W}_{\mathrm{v}} \\
\geq & 5 \mathrm{~m} \mathrm{~s}^{-1}\end{aligned}$ & $\begin{array}{c}\text { Intervalo de } \\
\text { duración } \\
\text { promedio horario } \\
\text { mensual }\end{array}$ & Fecha & $\begin{aligned} & \% \mathrm{~W}_{\mathrm{v}} \\
\geq & 5 \mathrm{~m} \mathrm{~s}^{-1}\end{aligned}$ & $\begin{array}{l}\text { Intervalo de } \\
\text { duración (hr) del día } \\
\text { de medición }\end{array}$ \\
\hline Abril & 2008 & 19,44 & $13: 00-17: 00$ & $05 / 04 / 08$ & 33,33 & $13: 00-20: 00$ \\
\hline Octubre & 2008 & 31,85 & $12: 00-19: 00$ & $16 / 10 / 08$ & 29,17 & $12: 00-18: 00$ \\
\hline Marzo & 2009 & 28,09 & 14:00-19:00 & $27 / 03 / 09$ & 37,50 & $12: 00-20: 00$ \\
\hline Agosto & 2009 & 17,47 & $15: 00$ & $28 / 08 / 09$ & 16,67 & $13: 00-16: 00$ \\
\hline Abril & 2010 & 23,09 & $13: 00-17: 00$ & $06 / 04 / 10$ & 45,83 & $11: 00-21: 00$ \\
\hline Agosto & 2010 & 16,53 & $11: 00$ & $10 / 08 / 10$ & 4,16 & $9: 00$ \\
\hline Marzo & 2011 & 24,19 & $14: 00-18: 00$ & $25 / 03 / 11$ & 33,33 & $14: 00-19: 00 ; 24: 00$ \\
\hline \multirow[t]{3}{*}{ Junio } & 2012 & 15,83 & - & $22 / 06 / 12$ & 0,00 & - \\
\hline & & & & $27 / 06 / 12$ & 29,16 & $14: 00-15: 00$ y $17: 00-20: 00$ \\
\hline & & & & $29 / 06 / 12$ & 16,66 & $16: 00-19: 00$ \\
\hline
\end{tabular}

Tabla 5. Dirección porcentual del viento sur (S), suroeste (SW), noroeste (NW) y norte (N), y porcentaje de la velocidad de la componente meridional $\geq 5 \mathrm{~m} \mathrm{~s}^{-1}$ para un período de 5 días previos a las fechas de muestreo e incluyendo esta última / South (S), Southwest (SW), Northwest (NW) and North (N) porcentual wind direction and porcentual of the meridional component $\geq 5 \mathrm{~m} \mathrm{~s}^{-1}$ for a period of 5 days previous of the dates of measurements and including this last one

\begin{tabular}{ccccccc}
\hline $\begin{array}{c}\text { Fecha de } \\
\text { muestreo }\end{array}$ & Período (5 días) & S (\%) & SW (\%) & NW (\%) & N (\%) & $\begin{array}{r}\% \mathrm{~W}_{\mathrm{v}} \geq \\
5 \mathrm{~m} \mathrm{~s}^{-1}\end{array}$ \\
\hline $05 / 04 / 2008$ & 1 al 5/04/2008 & 52,5 & 5,83 & 0 & 0,83 & 19,17 \\
$16 / 10 / 2008$ & 12 al 16/10/2008 & 57,5 & 21,67 & 2,5 & 5 & 30,0 \\
$27 / 03 / 2009$ & 23 al 27 /03/2009 & 54,17 & 5,83 & 0 & 0 & 25,83 \\
$28 / 08 / 2009$ & 24 al 28/08/2009 & 38,33 & 10,83 & 4,17 & 22,5 & 13,33 \\
$06 / 04 / 2010$ & 2 al 6/04/2010 & 80,0 & 4,17 & 0 & 0 & 29,17 \\
$10 / 08 / 2010$ & 6 al 10/08/2010 & 39,17 & 5,83 & 10,83 & 16,67 & 7,50 \\
$25 / 03 / 2011$ & 21 al 25/03/2011 & 55,83 & 7,5 & 0 & 5 & 23,33 \\
$29 / 06 / 2012$ & 25 al 29/06/2012 & 65,00 & 5,83 & 2,5 & 7,5 & 15,00 \\
\hline
\end{tabular}

las coordenadas $23^{\circ} 26^{\prime} \mathrm{S}$ y $70^{\circ} 26^{\prime} \mathrm{W}$, y a $135 \mathrm{~m}$ sobre el nivel del mar. Esta estación pertenece a la Dirección Meteorológica de Chile (Fig. 1), si bien se encuentra a una altura considerable sobre el nivel del mar los registros de vientos son los más representativos, de la BSJ y de la zona en general, que se tienen hasta el momento. Se adopta el valor de $5 \mathrm{~m} \mathrm{~s}^{-1}$ como velocidad límite a partir de la cual la componente meridional del viento es capaz de generar un ascenso de las aguas subsuperficiales, según Marín et al. (1993). A su vez, también se requiere un cierto grado de persistencia tanto en dirección como en intensidad de dicha componente del viento generadora de surgencia, de al menos $30 \mathrm{~h}$ para la latitud de $23^{\circ} \mathrm{S}$ (Barber \& Smith 1981). Sin embargo, como se verá en los resultados esto último no necesariamente se cumple en esta zona. 
Temperatura potencial $\left({ }^{\circ} \mathrm{C}\right)$

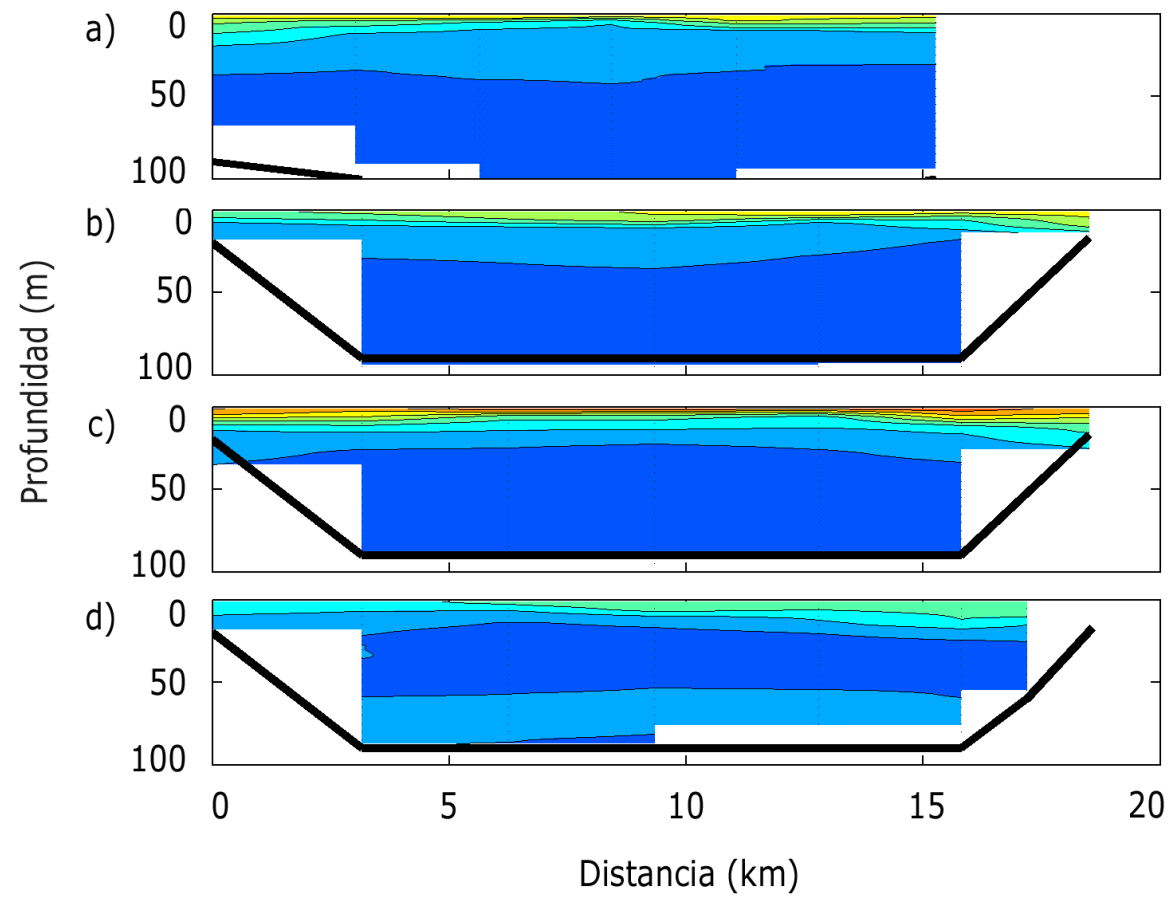

Temperatura potencial $\left({ }^{\circ} \mathrm{C}\right)$
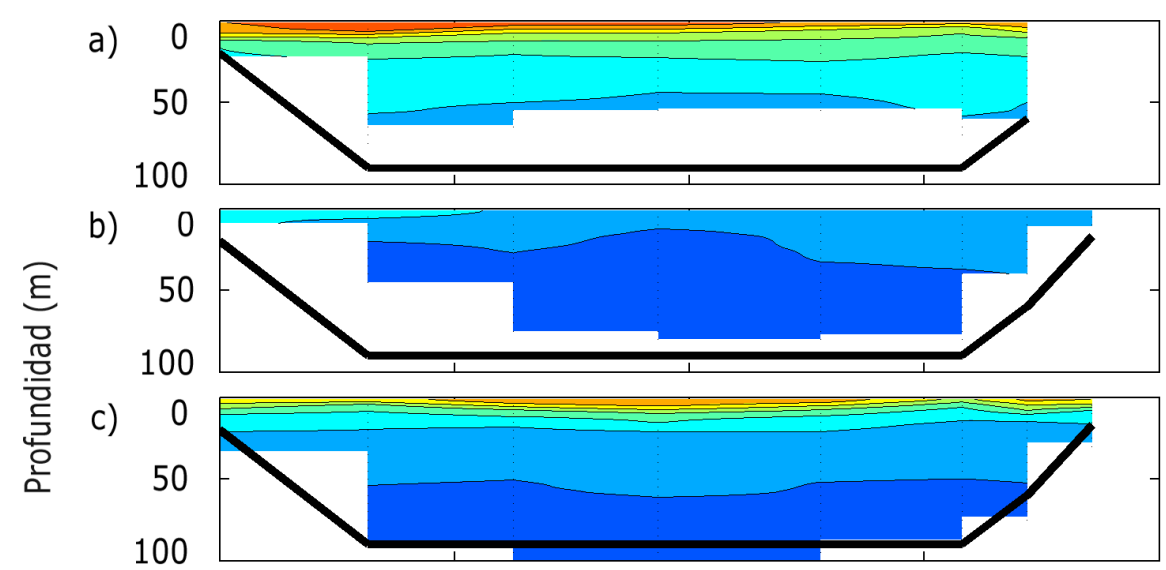

d)

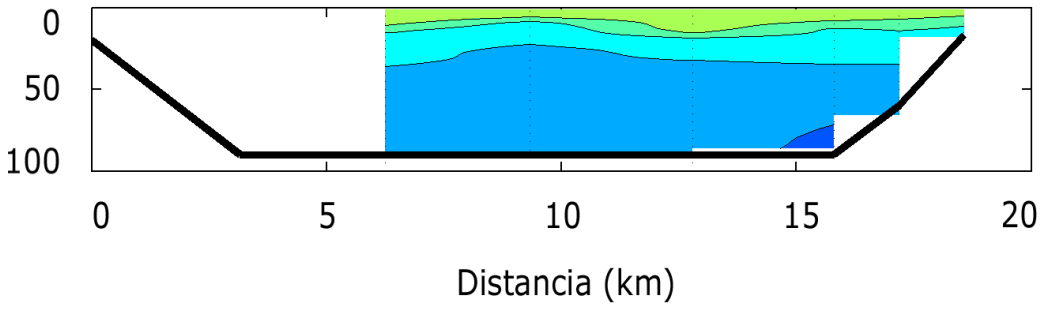

Figura 2. Distribución de la temperatura entre el Faro del Puerto de Antofagastay PuntaJorge (a) 05/04/2008, (b) 16/10/2008, (c) 2703/2009, y (d) 28/09/2009 / Temperature distribution for the section between Antofagasta Port Lighthouse and Punta Jorge (a) 05/04/2008, (b) $16 / 10 / 2008$, (c) $27 / 03 / 2009$, and (d) $28 / 08 /$ 2009

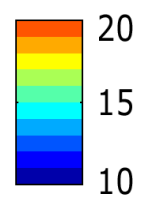

Figura 3. Distribución de la temperatura entre el Faro del Puerto de Antofagasta y Punta Jorge (a) 06/04/2010, (b) 10/08/ 2010 , (c) $25 / 03 / 2011$, y (d) 22,27 y $29 / 06$ 2012 / Temperature distribution for the section between Antofagasta Port Lighthouse and Punta Jorge (a) 06/04/ 2010, (b) 10/08/2010, (c) 25/03/2011, and (d) 22,27 and 29/06/2012 
Salinidad

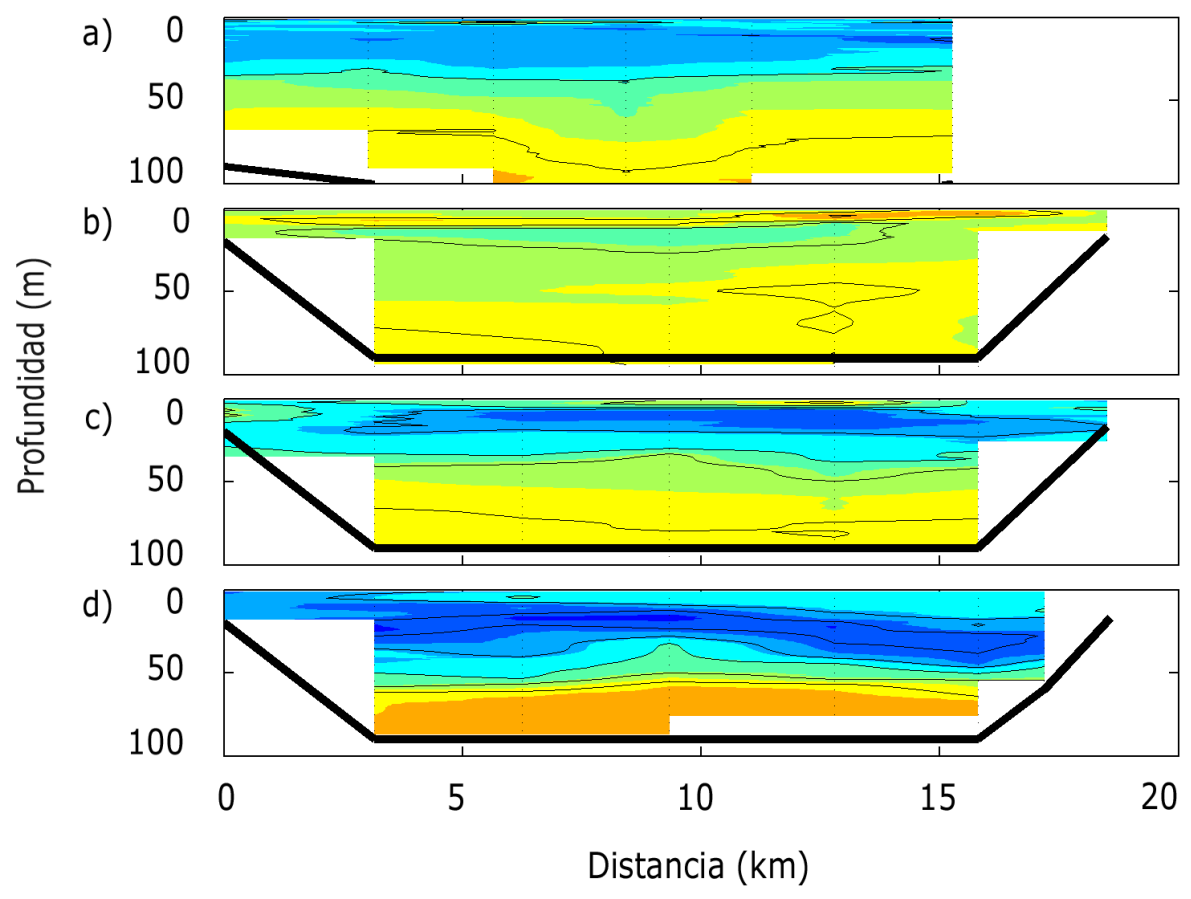

Salinidad

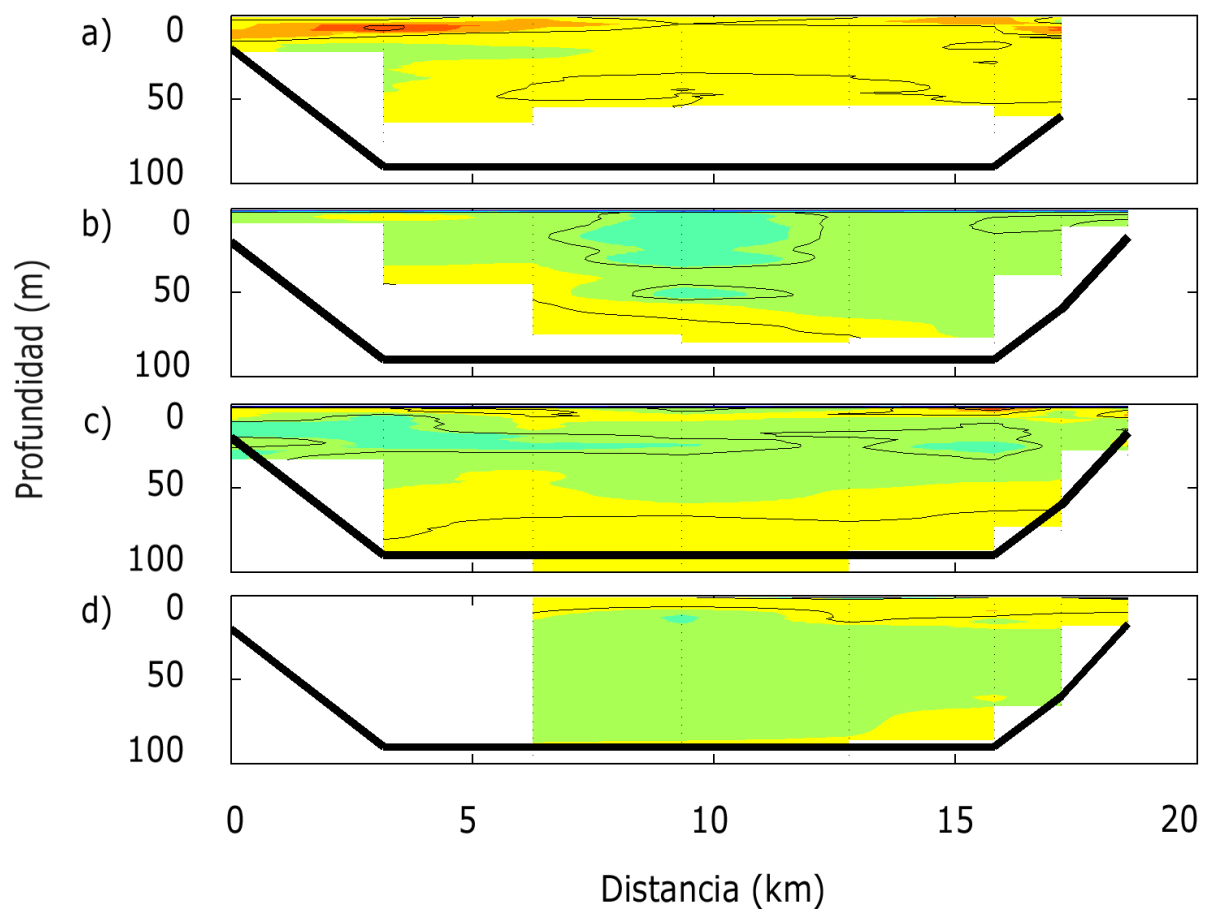

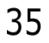

34,5

Figura 4. Distribución de la salinidad entre el Faro del Puerto de Antofagasta y Punta Jorge (a) $05 / 04 / 2008$, (b) $16 / 10 /$ 2008, (c) 2703/2009, y (d) 2808/2009 / Salinity distribution for the section between Antofagasta Port Lighthouse and Punta Jorge (a) 05/04/2008, (b) 16/ 10/2008, (c) 27/03/2009, and (d) 28/08/ 2009

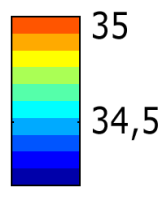

Figura 5. Distribución de la salinidad entre el Faro del Puerto de Antofagasta y Punta Jorge (a) 06/04/2010, (b) 10/08/ 2010 , (c) $25 / 03 / 2011$ y (d) 22,27 y $29 /$ $06 / 2012$ / Salinity distribution for the section between Antofagasta Port Lighthouse and Punta Jorge (a) 06/04/ 2010, (b) $10 / 08 / 2010$, (c) $25 / 03 / 2011$ and (d) 22, 27 and 29/06/2012 
$\sigma_{\mathrm{t}}\left(\mathrm{kg} \mathrm{m}^{-3}\right)$
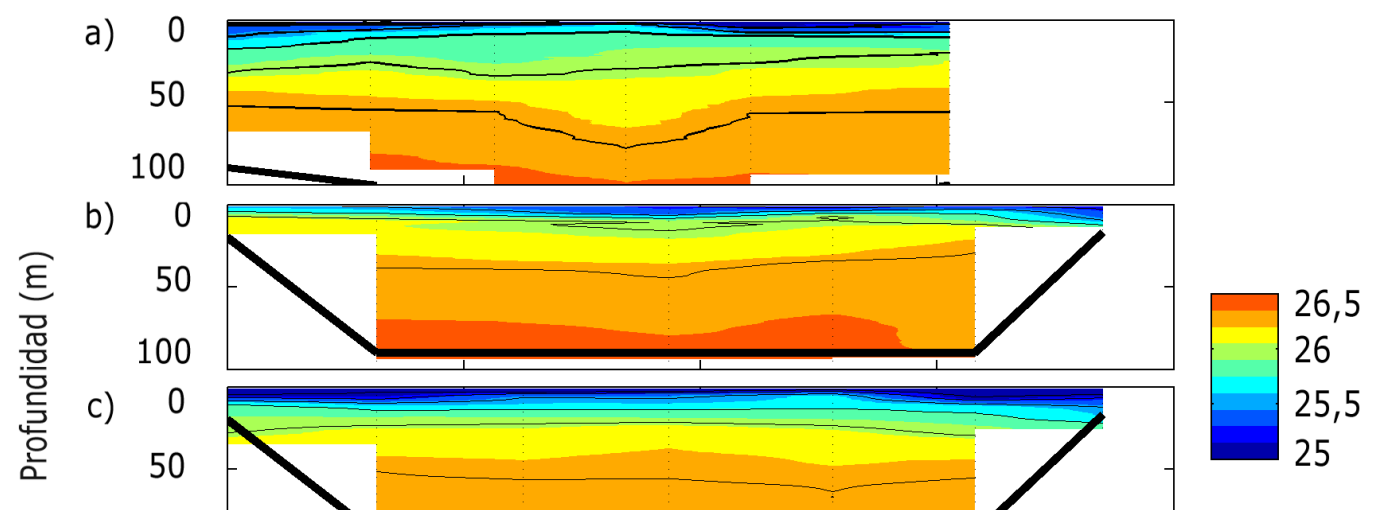

Figura 6. Distribución de la densidad (kg $\mathrm{m}^{-3}$ ) entre el Faro del Puerto de Antofagasta y Punta Jorge (a) 05/04/2008, (b) $16 / 10 / 2008$, (c) $27 / 03 / 2009$ y (d) $28 /$ 08/2009 / Density distribution $\left(\mathrm{kg} \mathrm{m}^{-3}\right)$ between Antofagasta Port Lighthouse and Punta Jorge (a) 05/04/2008, (b) 16/ 100

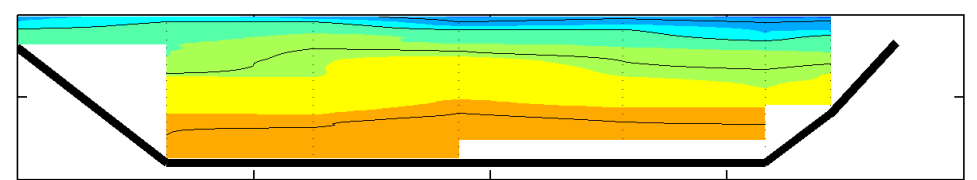

5

10

15 2009

Distancia $(\mathrm{km})$

$\sigma_{\mathrm{t}}\left(\mathrm{kg} \mathrm{m}^{-3}\right)$
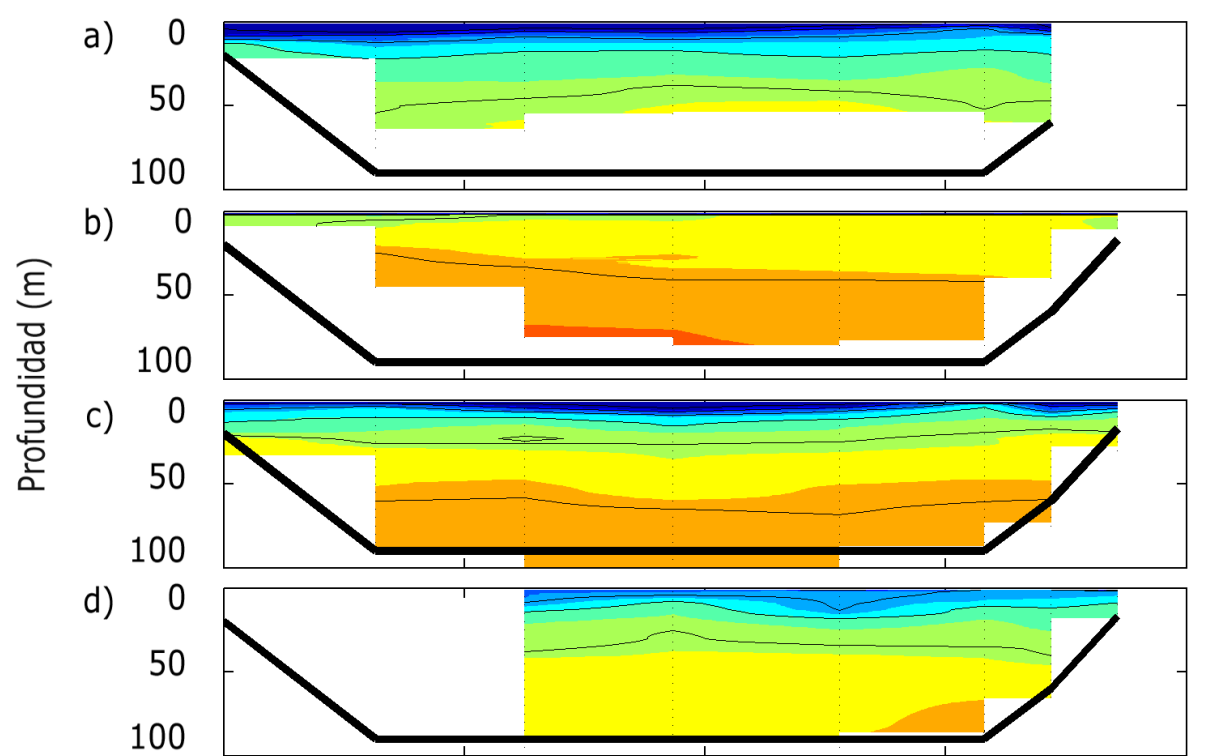

Figura 7. Distribución de la densidad $\left(\mathrm{kg} \mathrm{m}^{-3}\right)$ entre el Faro del Puerto de Antofagasta y Punta Jorge (a) 06/04/ 2010 , (b) $10 / 08 / 2010$, (c) $25 / 03 / 2011$ y (d) 22, 27 y 29/06/2012 / Density distribution $\left(\mathrm{kg} \mathrm{m}^{-3}\right)$ between Antofagasta Port Lighthouse and Punta Jorge (a) 06/04/2010, (b) 10/08/ 0

Distancia $(\mathrm{km})$ 
(a) $05 / 04 / 2008$

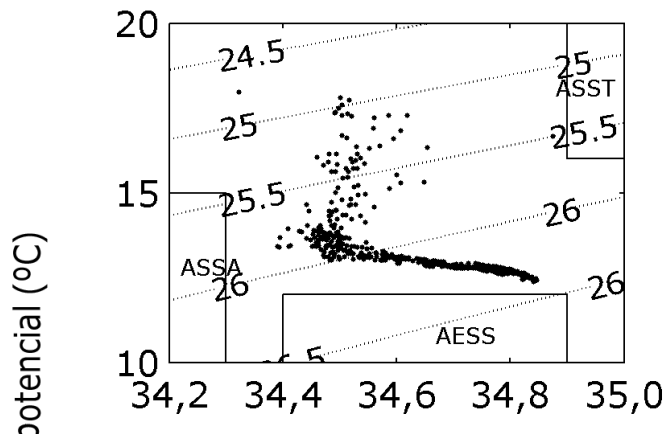

(c) $27 / 03 / 2009$

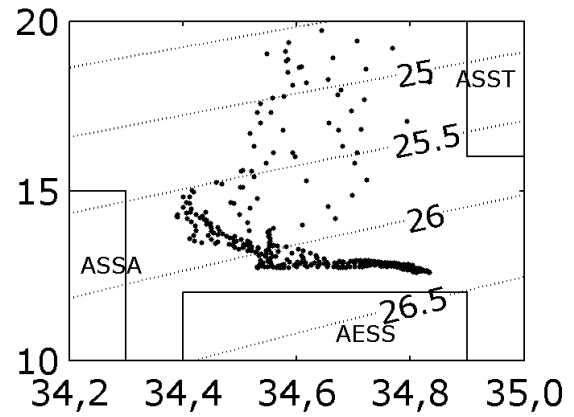

(b) $16 / 10 / 2008$

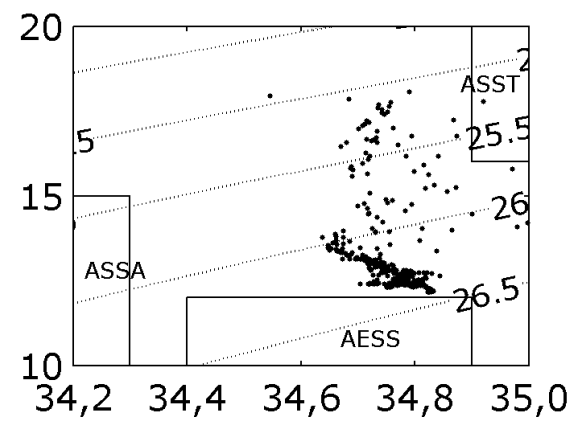

(d) $28 / 08 / 2009$

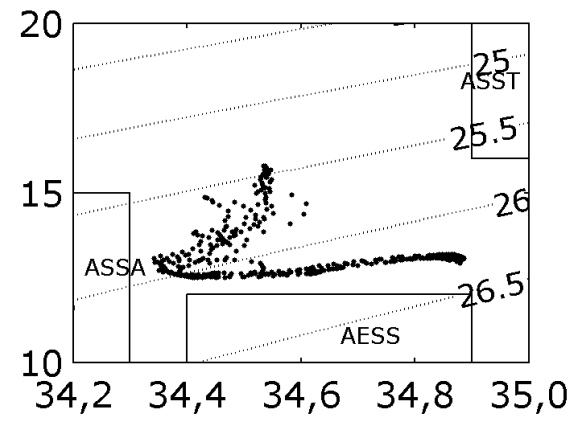

Figura 8. Diagrama T-S obtenidos durante los siguientes períodos de estudio: (a) 5/04/2008, (b) 16/ $10 / 2008$, (c) $2703 / 2009$ y (d) $28 /$ 08/2009 / T-S diagrams obtained on the following study periods: (a) $05 / 04 / 2008$, (b) $16 / 10 / 2008$,

(c) $27 / 03 / 2009$ y (d) $28 / 08 / 2009$

Salinidad

(a) $06 / 04 / 2010$
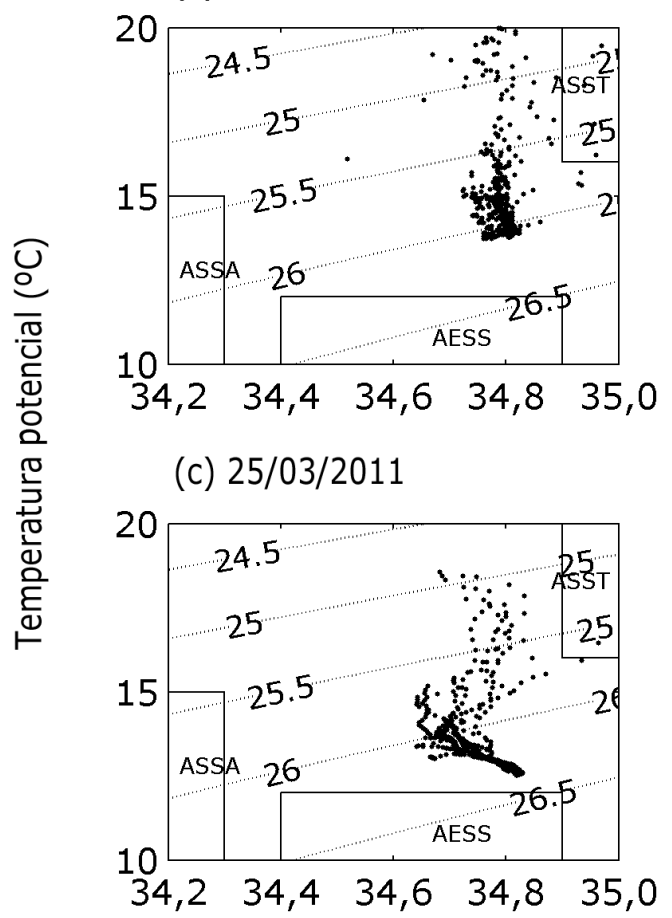

(b) $10 / 08 / 2010$

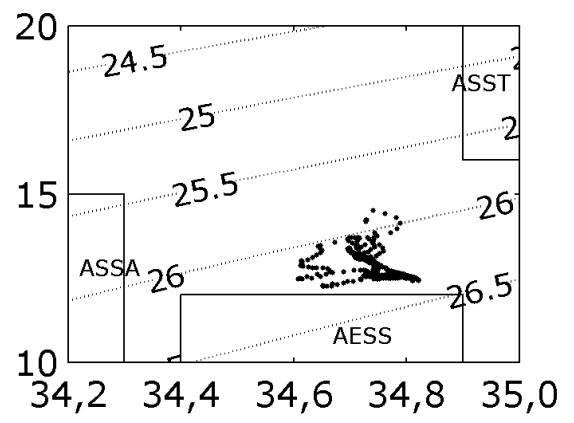

(d) $22,27,29 / 06 / 2012$

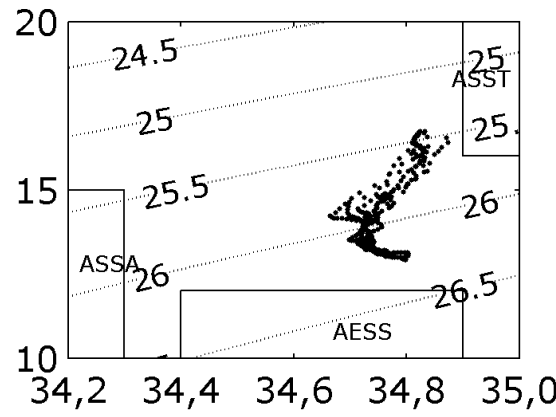

Figura 9. Diagrama T-S obtenidos durante los siguientes períodos de estudio: (a) 06/04/2010, (b) 10/ $08 / 2010$, (c) $25 / 03 / 2011$ y (d) 22 , 27 y 29/06/2012 / T-S diagrams obtained on the following study periods: (a) 06/04/2010, (b) $10 /$ $08 / 2010$, (c) $25 / 03 / 2011$ and (d) 22, 27 and 29/06/2012 


\section{Resultados}

\section{Hidrografía}

Las distribuciones de temperatura, salinidad y sigma t de los 8 muestreos evidencian una capa estratificada desde la superficie hasta $\operatorname{los} 18-20 \mathrm{~m}$ de profundidad aproximadamente producto de una termoclina bien marcada (Figs. 2-7). La temperatura superficial varió entre 14,5 y $20^{\circ} \mathrm{C}$ en promedio. Entre los 20 y $90 \mathrm{~m}$ de profundidad, la distribución de la temperatura fue de mayor homogeneidad en todos los períodos, observándose valores entre 12 y $14^{\circ} \mathrm{C}$. En la fecha representativa de invierno (28 de agosto 2009), la distribución de la temperatura, mostró un debilitamiento de la termoclina en los primeros $25 \mathrm{~m}$ de la columna de agua, en relación a las otras fechas de muestreo, observándose un gradiente vertical de temperatura de $4,4 \times 10^{-3}{ }^{\circ} \mathrm{C} \mathrm{m}^{-1}$. Además, en dicha fecha se observa una capa de mezcla promedio de $2,14 \pm 1,57 \mathrm{~m}$ y una capa estratificada de 4,71 $\pm 3,59 \mathrm{~m}$ (Tabla 2).

La distribución general de la salinidad (Figs. 4 y 5) varía entre 34,32 y 35,35 considerando los 8 muestreos. Se observan diferentes patrones de distribución vertical según la fecha de estudio. En varios muestreos la isohalina de 34,6 divide a la columna de agua en 2 capas (una superficial y otra profunda). Durante el 5 de abril 2008 y 27 de marzo 2009, la isohalina de 34,6 se ubica entre los 35 a 38 m mientras que en la medición del 28 de agosto 2009 se profundiza (40-50 m). En la capa superficial la salinidad ronda el valor de 34,5 a pesar que durante el 5 de abril 2008, se aprecia una estrecha capa cercana a la superficie de mayor salinidad que en la zona central, con valores $\geq 34,6$. Esta lengua de alta salinidad amplifica su extensión y profundidad durante marzo 2009, alcanzando valores entre 34,7 y 34,8 . A su vez, la capa profunda presentó una salinidad elevada, con valores mayores a 34,6 y en ciertos casos sobrepasa el valor de 35 . En las distribuciones de salinidad del 16 de octubre 2008, 6 de abril 2010, 10 de agosto 2010 y 25 de marzo 2011, las características de la salinidad fueron de mayor homogeneidad en toda la columna de agua. Por ejemplo, durante el 6 de abril 2009 los valores de salinidad varían entre 34,7 y 34,9, observándose valores < 34,7 en la zona central de la bahía y/o en los niveles subsuperficiales, alrededor de los $15 \mathrm{~m}$.

La distribución de la densidad (sigma-t) presentó una columna de agua estratificada, especialmente en los primeros $20 \mathrm{~m}$ en la mayoría de los muestreos con excepción del 10 de agosto 2010 (Figs. 6 y 7). Dicha estratificación se debe principalmente a la distribución estratificada de la temperatura (Figs. 2 y 3), a pesar que la salinidad también ejerce su influencia especialmente durante las mediciones representativas del período de verano (5 de abril 2008, 27 de marzo 2009).

La capa estratificada presentó un espesor promedio mayor a $10 \mathrm{~m}$ durante el verano tardío (marzo 2009, abril 2010 y marzo 2011), siendo el espesor promedio máximo de 13,28 \pm 4,34 m en marzo 2009 y el espesor promedio mínimo de 1,37 m durante agosto 2010 (Tabla 2). A su vez, en el resto de las fechas de muestreo se obtienen valores entre 4,71 y $8,5 \mathrm{~m}$ de espesor. Como es de esperar los valores $\Phi_{\mathrm{s}}$ del parámetro de estratificación (Tabla 2) poseen la misma distribución temporal que la capa estratificada, indicando que se requiere mayor energía para romper dicha capa durante el verano. El máximo valor medio fue de 70,96 $\pm 24,70\left(\mathrm{~J} \mathrm{~m}^{-3}\right)$ durante el 27 de marzo 2009 y el mínimo de $13,81 \pm 8,79\left(\mathrm{~J} \mathrm{~m}^{-3}\right)$ el 10 de agosto 2010. El grosor promedio de la capa de mezcla se observa preferentemente en los períodos de invierno (junio 2012 con $8,2 \mathrm{~m}$ y agosto 2010 con $6,85 \mathrm{~m}$ ) observándose en este último período una estación con un espesor de capa de mezcla de $18 \mathrm{~m}$.

\section{Masas de agua}

Los diagramas T_S de los 8 períodos estudiados (Figs. 8 y 9) sugieren presencia e interacción del ASST, ASSA, y AESS, con un predominio permanente de esta última masa de agua en la capa inferior, pudiendo encontrarse también en el nivel intermedio y en menor medida en la capa superficial, esto debido a que los puntos del diagrama T_S están cercanos a los índices termohalinos que definen a estas masas de agua de acuerdo a Sobarzo \& Figueroa (2001). Se identificó la presencia de ASST (16$24^{\circ} \mathrm{C}$ y $\left.34,9-35,3\right)$, ASSA $\left(9-15^{\circ} \mathrm{C}\right.$ y $\left.33-34,3\right)$ y AESS $(8-$ $12^{\circ} \mathrm{C}$ y $\left.34,4-34,9\right)$, constituyendo modificaciones de las mismas considerando que la bahía es un cuerpo semicerrado predispuesto a una mayor mezcla, debido a que los pares de puntos de temperatura y salinidad, obtenidos de los perfiles, al graficarlos en el diagrama T_S no necesariamente se ubican dentro de los rangos de los índices termohalinos definidos para cada una de las masas de agua. Sin embargo, el grado de influencia de las masas de agua puede variar según la época del año llegando incluso a registrarse solamente la presencia de 1 ó 2 masas de agua. Si bien el AESS está presente en la mayoría de las fechas de muestreo dicha masa de agua no se observa con tanta claridad el 6 de abril 2010 (Fig. 9), debido a que en dicho período los perfiles de CTD se 
realizaron hasta $10 \mathrm{~s} 60$ a $70 \mathrm{~m}$ de profundidad no lográndose captar por completo la zona más profunda en donde se ubica esta masa de agua. Cabe agregar que el rango de salinidad observado en los distintos diagramas T_S está dentro del rango teórico del AESS según Sobarzo \& Figueroa (2001), mientras que la temperatura en general está sobre los $12^{\circ} \mathrm{C}$, límite crítico superior para definir esta masa de agua. En la capa superficial de la BSJ es posible encontrar ya sea ASST o ASSA. El ASST se destaca preferentemente en la época cálida (octubre 2008, abril 2010 y marzo 2011) (Figs. 8 y 9). Por otra parte el ASSA no muestra un patrón temporal definido en cuanto a su presencia, ya que sus máximos porcentajes se ubican en la superficie y luego decrecen con la profundidad. Dicha masa de agua estaría presente tanto en la capa superficial como en los niveles intermedios. Se observa además que estas 2 masas de agua estuvieron presentes simultáneamente en marzo 2009 (Fig. 8c). Por otra parte, destaca el hecho que en agosto 2010 (Fig. 9b) hubo un predominio de AESS en toda la columna de agua, observándose las temperaturas más bajas en superficie (aproximadamente $14,5^{\circ} \mathrm{C}$ ) de todos los períodos muestreados. Cabe mencionar que en invierno las temperaturas superficiales descienden por debajo de los $16^{\circ} \mathrm{C}$ mientras que, durante la época cálida, estas se mantuvieron entre 18 y $20^{\circ} \mathrm{C}$. Sin embargo, los esquemas de salinidad y temperatura potencial versus contenido de oxígeno disuelto (Fig. 10), obtenidos para los últimos 3 muestreos, permiten diferenciar de mejor manera tanto el AESS como el ASST. En efecto, al considerar la totalidad de los períodos muestreados y para el rango de contenido de oxígeno disuelto entre 0 a $2 \mathrm{ml} \mathrm{L}^{-1}$, la salinidad fluctuó entre 34,6 a 34,8 y la temperatura entre 11,9 y $15^{\circ} \mathrm{C}$, valores próximos a los rangos que caracterizan al AESS. A su vez el ASST se identifica por el contenido de oxígeno disuelto igual o superior a $4,5 \mathrm{ml} \mathrm{L}^{-1}$, una salinidad superior a 34,8 con temperaturas superiores a $16^{\circ} \mathrm{C}$ (marzo 2011 y junio 2012). (a) $10 / 08 / 2010$

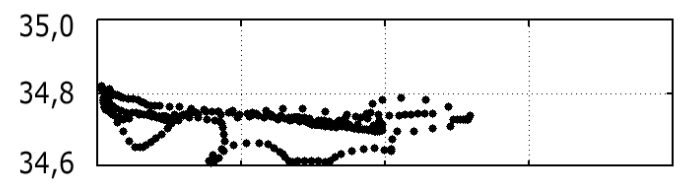

(c) $25 / 03 / 2011$

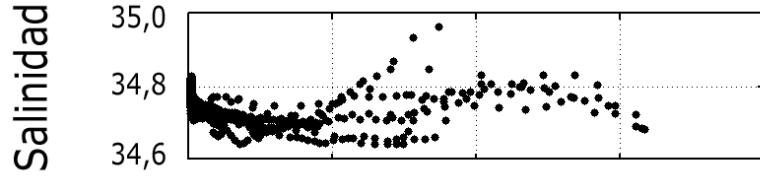

(e) $22,27,29 / 06 / 2012$

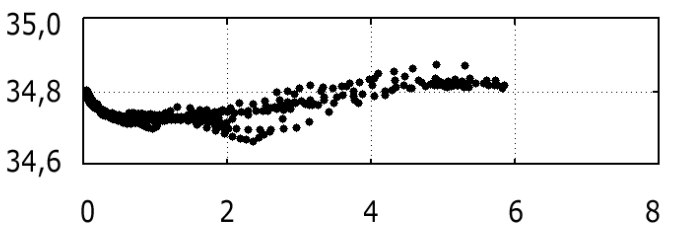

(b) $10 / 08 / 2010$

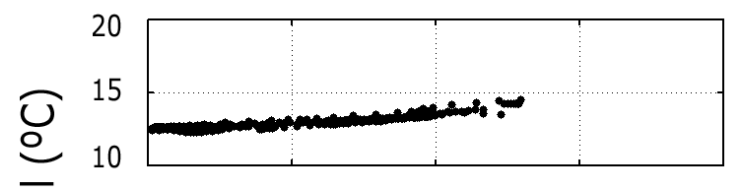

(d) $25 / 03 / 2011$

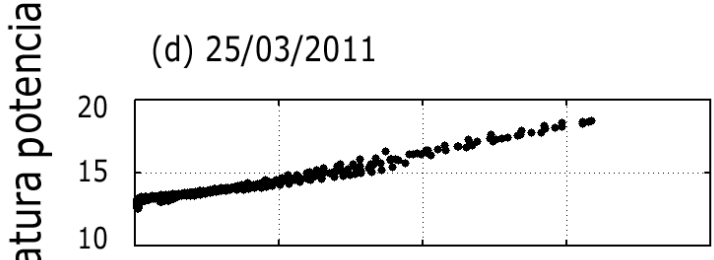

(f) $22,27,29 / 06 / 2012$

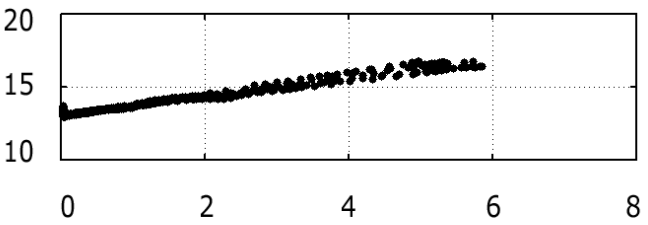

$$
\mathrm{O}_{2} \text { disuelto }\left(\mathrm{ml} \mathrm{L}^{-1}\right)
$$

Figura 10. Esquemas de salinidad versus contenido de oxígeno disuelto y temperatura potencial versus contenido de oxígeno disuelto, para los períodos: 10/08/2010 (a y b), 25/03/2011 (c y d) y 22, 27 y 29/06/2012 (e y f) / Schemes of salinity versus dissolved oxygen content and potential temperature versus dissolved oxygen content, for the following periods: 10/08/2010 (a and b), 25/03/2011 (c and d) and 22, 27 and 29/06/2012 (e and f) 
$\%$ Masas de agua

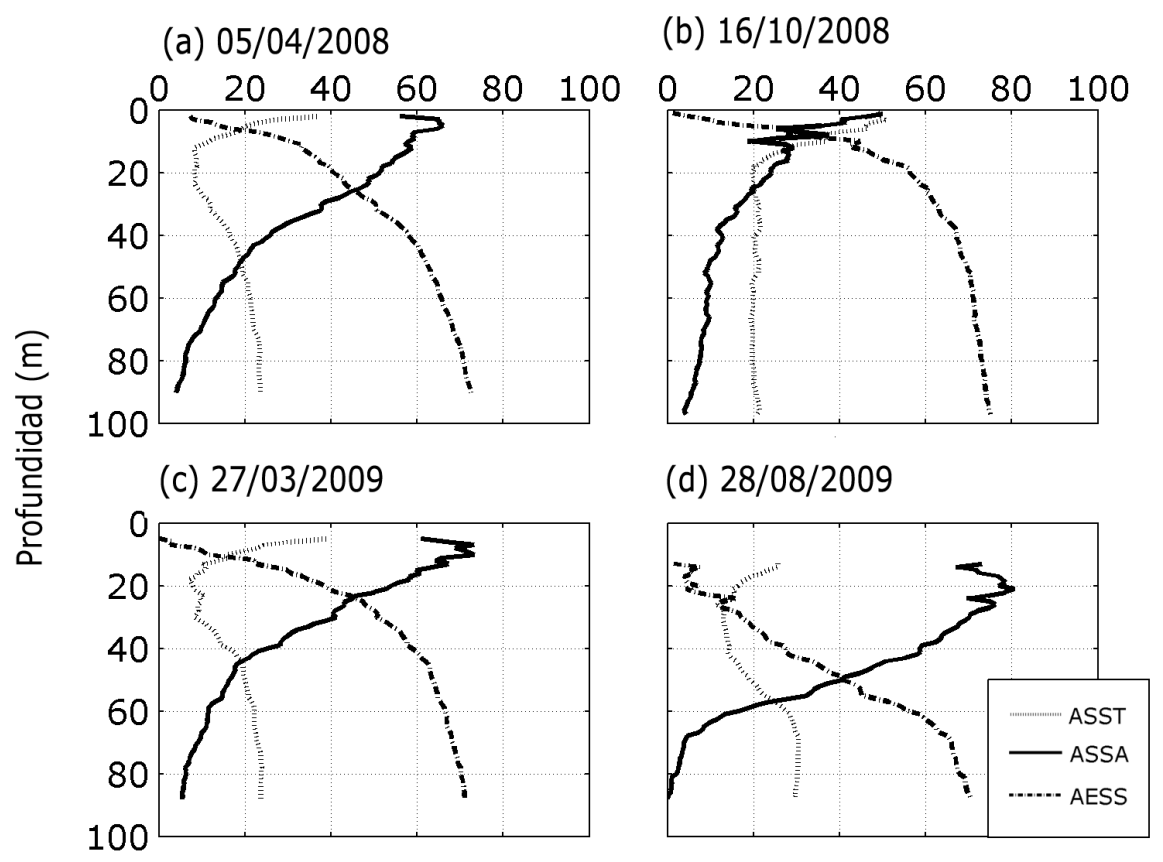

Figura 11. Distribución porcentual de las masas de agua obtenidas para cada uno de los períodos de estudio: (a) 05/04/2008, (b) $16 / 10 / 2008$, (c) $27 / 03 / 2009$ y (d) $28 / 08 / 2009$ / Percentage distribution of water masses obtained for each study period: (a) 05/04/ 2008 , (b) $16 / 10 / 2008$, (c) $27 / 03 / 2009$ and (d) $28 / 08 / 2009$

$\%$ Masas de agua

(a) $06 / 04 / 2010$

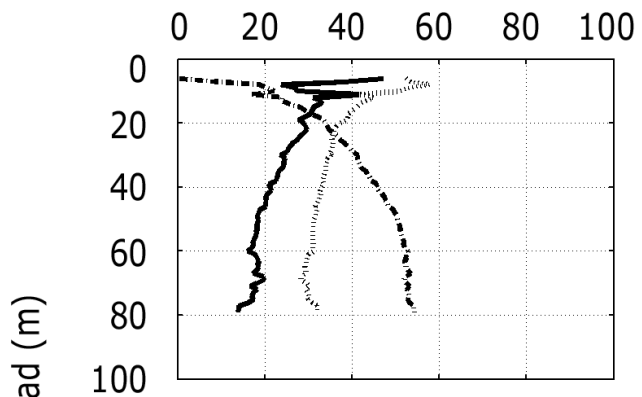

(c) $25 / 03 / 2011$

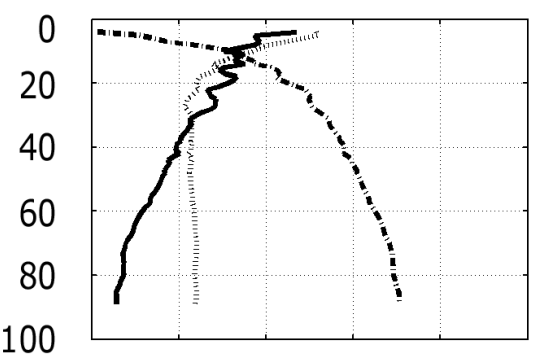

(b) $10 / 08 / 2010$

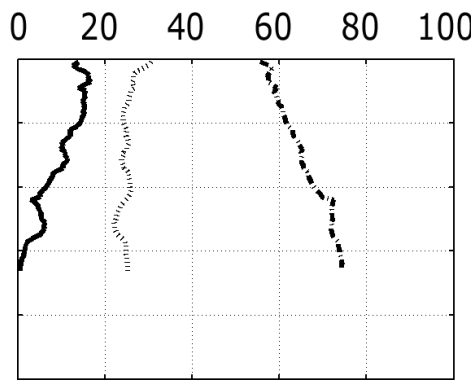

(d) $27 / 06 / 2012$

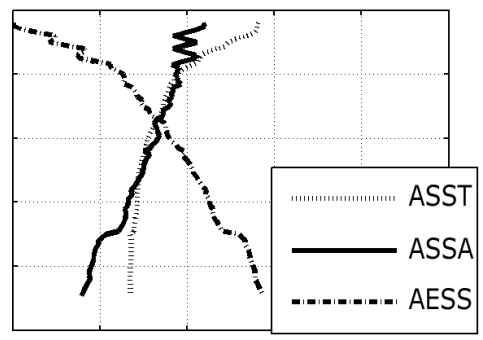

Figura 12. Distribución porcentual de las masas de agua obtenidas para cada uno de los períodos de estudio: (a) 06/04/2010, (b) 10/08/2010, (c) 25/03/2011 y (d) 22, 27 and 29/06/2012 (indicado como 27) / Percentage distribution of water masses obtained for each study period: (a) 06/04/2010, (b) 10/08/ 2010, (c) 25/03/2011 and (d) 22, 27 and 29/ 06/2012 (indicated as 27) 
En relación a la distribución vertical del porcentaje de masas de agua (Figs. 11 y 12) se observó que en la capa superficial predomina el ASST y el ASSA, con porcentajes variables según el período de estudio. Si bien no existe un patrón temporal definido en cuanto al porcentaje que presenta cada una en la capa superficial, se observan en 2 ocasiones del verano tardío (6 de abril 2010 y 25 de marzo 2011) otro durante el período cercano a la primavera (16 de octubre 2008) como así también en agosto 2010 y junio 2012, donde el porcentaje del ASST fue superior al de ASSA. Por ejemplo, el 16 de octubre 2008 el porcentaje promedio de ASSA fue de 43,69\% versus aquel de ASST de $35,07 \%$ en la capa de 1 a $10 \mathrm{~m}$, mientras que el 6 de abril 2010 el porcentaje promedio de ASSA fue de 53,33\% versus $32,65 \%$ de ASST para una capa de 6-10 m de profundidad. La distribución vertical del ASSA es máxima en superficie y decrece con la profundidad. Al menos en 3 ocasiones el ASSA domina la capa superficial (primeros $20 \mathrm{~m}$ ) con porcentajes mayores al 55\% (5 de abril 2008, 27 de marzo 2009 y 28 de agosto 2009). Por otra parte, el AESS presentó una distribución con porcentajes mínimos en superficie los cuales se incrementan con la profundidad siendo estos del orden del 70\% aproximadamente en la capa de 70-80 m. A excepción del 10 de agosto 2010, donde se aprecian porcentajes mayores al $50 \%$ en toda la columna de agua, indicando un proceso de mezcla posiblemente por efecto de enfriamiento de la capa superficial que genera incrementos de densidad y movimientos convectivos. Sin embargo, el contenido de oxígeno disuelto permite distinguir además del AESS otra masa de agua con mayor contenido de oxígeno disuelto, o la existencia de un mecanismo de ventilación de las aguas en superficie. De acuerdo a los análisis de datos de viento realizados en períodos de 5 días anteriores a la fecha de muestreo, pero que incluyen a esa fecha (Tabla 5), no se observan condiciones propicias para la surgencia en relación a otros períodos estudiados dado que el porcentaje de velocidad de viento favorable a la surgencia es sólo del 7,5\%, y la dirección del viento favorable para este proceso fue sólo del $45 \%$ y un corto lapso de tiempo en el cual esta velocidad propicia para la surgencia tiene lugar.

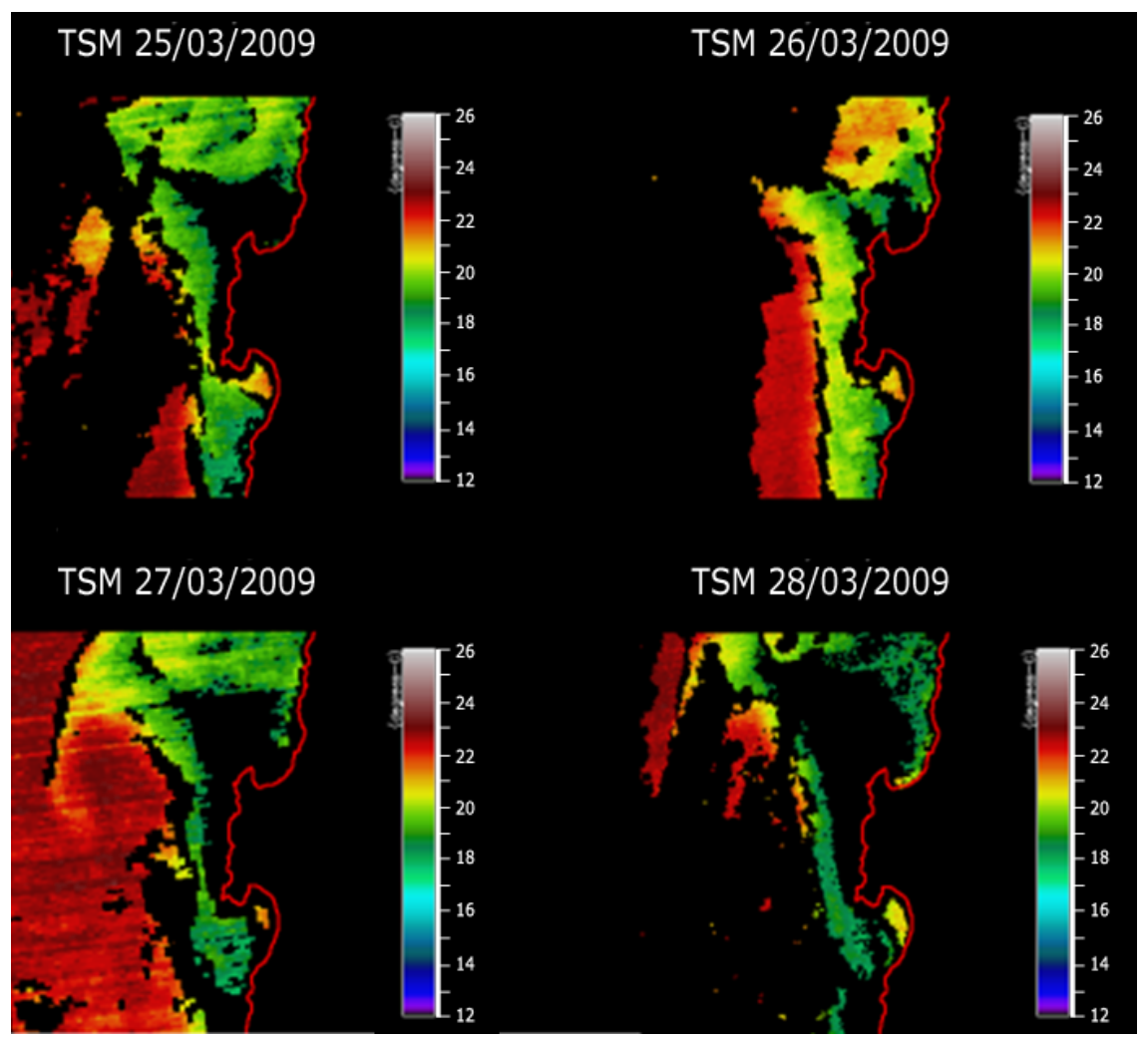

Figura 13. Imágenes satelitales de TSM MODIS AQUA del área frente a la Península de Mejillones para el período del 25 al 28 de marzo 2009 / MODIS AQUA SST satellite images corresponding to Península de Mejillones for the period starting on the $25^{\text {rd }}$ till the $28^{\text {th }}$ of March 2009 
En la Fig. 13 se muestra una sucesión de imágenes de TSM entre el 25 al 28 de marzo a modo de ejemplo. La temperatura de las aguas frente a la costa, fue inferior con respecto a la oceánica entre 2 a $3^{\circ} \mathrm{C}$, lo cual podría atribuirse a los procesos de surgencia costera. En particular el 25 de marzo 2009, las aguas presentaron estructuras de aguas frías de $16-17^{\circ} \mathrm{C}$, al sur de la Bahía San Jorge (Punta Coloso), mientras que al interior de la misma, la temperatura varió entre 20 y $22^{\circ} \mathrm{C}$. Todas estas características refuerzan la idea que en la bahía y en marzo es factible encontrar la presencia de 3 masas de agua (ASST, ASSA y AESS) que son consecuencia de la interacción de los procesos de surgencia y del sistema de corriente frente a la bahía, debido a que interacciona un flujo hacia el sur y otro hacia el norte responsable del transporte de ASST y ASSA respectivamente, además del transporte de AESS previo a su ascenso a la superficie en los focos de surgencia de Punta Angamos y Punta Coloso.

\section{VIENTOS}

La distribución promedio horaria del viento mostró un predominio de la componente meridional sobre la zonal, además de que dicha componente incrementa su intensidad durante intervalos de tiempo diurnos, observándose una variación diaria pulsátil. Por ejemplo en abril 2008 (Fig. 14), la componente meridional promedio mostró una mayor intensidad del viento entre las 10:00 y 20:00 h, alcanzando intensidades promedio mayores a 5 $\mathrm{m} \mathrm{s}^{-1}$, entre las 13:00 y 18:00 h. Características similares se observan para 3 días del mes de abril. La Tabla 4 muestra el porcentaje de velocidad de la componente meridional del viento superior a $5 \mathrm{~m} \mathrm{~s}^{-1}$ y el intervalo de duración promedio diario del mes. En dicha tabla también se muestran estos datos para las fechas exactas de medición de las variables oceanográficas. Se observa claramente que las características del viento pueden ser agrupadas en 2. En el primer grupo se distinguen aquellos meses que presenta un alto porcentaje de predominio de las direcciones $\mathrm{S}$ y $\mathrm{SW}$, con un alto porcentaje de intensidad superior a $5 \mathrm{~m} \mathrm{~s}^{-1}$, además de presentar esta velocidad durante un período extenso del día, es decir entre las 12:00 y 18:00 h o incluso en un intervalo de mayor extensión horaria. A este primer grupo pertenecen los meses de primavera, verano y otoño. Dentro de este grupo se destaca octubre 2008, dado que muestra un claro predominio del viento de dirección S y SW. La velocidad de la componente meridional del viento registra valores > $5 \mathrm{~m} \mathrm{~s}^{-1}$ durante un intervalo extendido en el día (12:00-
19:00 h). El comportamiento del viento en el caso particular del 16 de octubre 2008 es similar a las del propio mes con una forzante del viento favorable a la surgencia costera mayoritariamente durante el período diurno. Los días previos también presentaron un comportamiento similar (Fig. 15). Abril 2010 y marzo 2011 son un ejemplo más de este primer grupo representando condiciones de un verano tardío, destacando las frecuencias $\mathrm{S}$ y $\mathrm{SW}$ del viento con un 60,13 y $13,33 \%$, respectivamente, para abril 2010 y de 57,93 y 4,70\%, respectivamente para marzo 2011 (Tabla 4). La velocidad de la componente meridional igual o superior a $5 \mathrm{~m} \mathrm{~s}^{-1}$ se registra con un $23,09 \%$ y en un $24,19 \%$, para abril 2010 y marzo 2011, respectivamente (Tabla 3). Por otra parte, el segundo grupo, se manifiesta en invierno, preferentemente en junio, julio y agosto, donde se observa que las frecuencias $\mathrm{S}$ y SW continúan siendo las direcciones del viento predominantes. Sin embargo la frecuencia sumada de las direcciones N y NW se incrementan en relación a los meses del grupo uno (Tabla 3). Además se observó una disminución del porcentaje de la velocidad de la componente meridional superior a $5 \mathrm{~m} \mathrm{~s}^{-1}$ como así también una disminución en el intervalo de tiempo promedio diario donde esta tendría lugar. En este estudio se observó este comportamiento con claridad en agosto. En efecto, agosto 2009 se caracterizó por el predominio de las direcciones $\mathrm{S}$ (47,98\%), SW (14,92\%), N (10,62\%), NW (3,76\%) (Tabla $3)$. La velocidad de la componente meridional fue superior a $5 \mathrm{~m} \mathrm{~s}^{-1}$ en un $17,47 \%$ sólo a las 15:00 h (Tabla 4). Resultados similares se aprecian en agosto 2010 y junio 2012 (Tablas 3, 4 y 5).

\section{Discusión}

Las características hidrográficas del área estudiada permiten observar patrones típicos de verano e invierno. Esto se manifiesta en la columna de agua a través del grosor de la capa estratificada, que está más y menos desarrollada durante el período de verano e invierno, respectivamente. Dicho comportamiento se refleja en el parámetro de estratificación el cual adquiere un mayor y menor valor, como es de esperar, en los períodos de verano e invierno, respectivamente. Por otra parte el grosor de la capa de mezcla presenta un comportamiento inverso al de la capa estratificada y parámetro de estratificación (Stewart 2003).

En la BSJ se identifican 3 masas de agua, ASSA, ASST y AESS, modificadas debido a distintos procesos físicos que tienen lugar en la bahía y/o fuera de ella, como por ejemplo los procesos de mezcla versus estratificación que 
(a) Componente zonal (abril 2008)

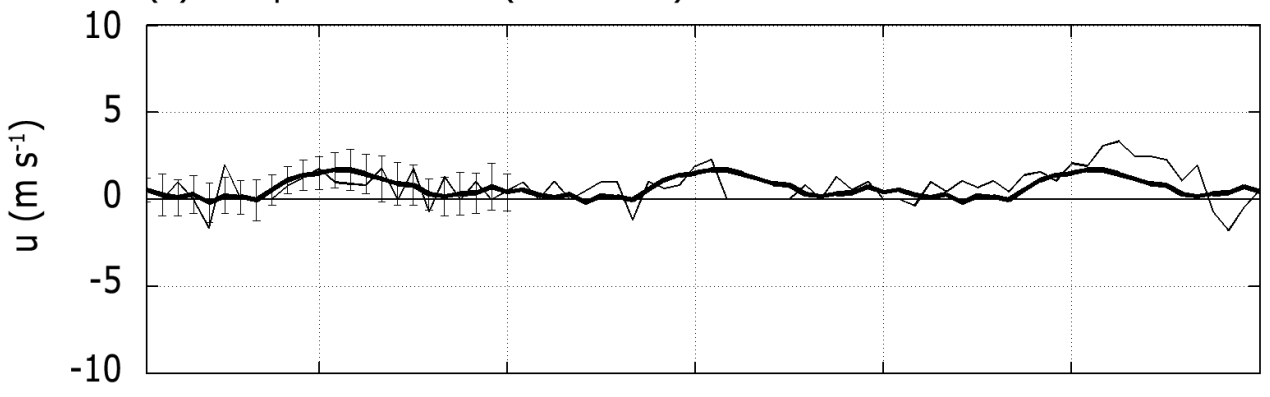

(b) Componente meridional (abril 2008)

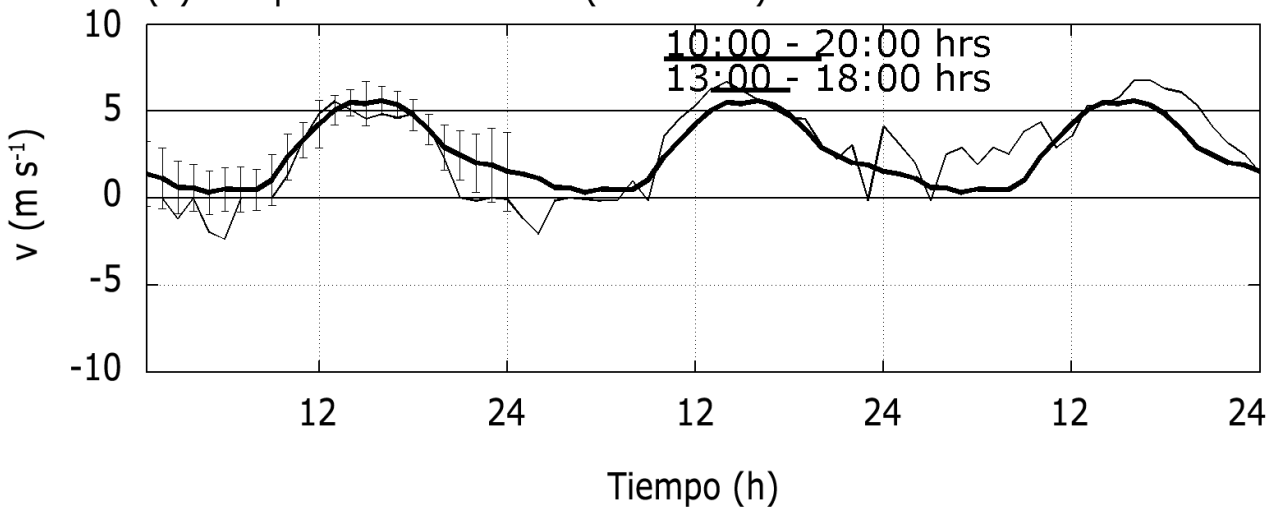

Figura 14. Características del viento para abril 2008: (a) Promedio horario mensual de la componente zonal (línea gruesa) con su respectiva desviación estándar y componente zonal horaria para 3 días consecutivos (línea fina), correspondiendo el último día, al de medición (05/04/ 2008), (b) Promedio horario mensual de la componente meridional con su respectiva desviación estándar horaria (línea gruesa) y componente meridional del viento horaria para 3 días consecutivos (línea fina), correspondiendo el último día, al de medición. Se señala el intervalo de duración de la intensidad de la componente meridional del viento mayor a $5 \mathrm{~m} \mathrm{~s}^{-1}$, es decir entre las 13:00 y 18:00 horas, y el intervalo general de mayor intensidad de la componente meridional del viento entre las 10:00 y 20:00 horas / Wind characteristics for April 2008: (a) Monthly hour mean zonal component (wide line) and its standard deviation and hourly zonal component for 3 days (thin line), being the last one, the day of observation (05/04/2008). (b) Monthly hour mean meridional component (wide line) and its standard deviation and hourly meridional component for 3 days (thin line), being the last one, the day of observation. The interval duration of the meridional mean wind component greater than $5 \mathrm{~m} \mathrm{~s}^{-1}$ takes place between 13:00 and 18:00 hours, while the general interval time of high intensity for this wind component is between 10:00 and 20:00 hours

se manifiestan en invierno y verano respectivamente, los procesos de surgencia preferentemente en primavera verano, y la dinámica de las corrientes costeras superficiales y corriente subsuperficial, como se discutirá en la presente sección. La variabilidad temporal de las masas de agua, en superficie, puede atribuirse a los procesos de mezcla versus estratificación, que tienen lugar en la capa de 0-20 m aproximadamente, destacándose en invierno (junio-agosto) y en un verano extendido (octubre-abril), respectivamente. Tal como queda evidenciado en los grosores de las capas estratificadas y de mezcla (Tabla 2) como así también en los valores del parámetro de estratificación siendo estos máximos en verano $\left(70,96 \pm 24,70 \mathrm{~J} \mathrm{~m}^{-3}\right.$, marzo 2009) y mínimos en invierno (13,81 $\pm 8,79 \mathrm{~J} \mathrm{~m}^{-3}$, agosto 2010). La mezcla vertical no solo se desarrolla por efecto de la turbulencia debido al viento sino también por efecto de enfriamiento de la capa superficial del agua en invierno (Stewart 2003), que genera movimientos convectivos y posibilitando el ascenso del AESS a niveles cercanos a la superficie en el interior de la bahía. Esto último, se manifiesta en agosto 2010 donde se observa un valor mínimo para el parámetro de estratificación $\left(13,81 \pm 8,79 \mathrm{~J} \mathrm{~m}^{-3}\right)$ y grosor de la capa estratificada $(1,57 \pm 1,40 \mathrm{~m})$, mientras que el espesor de la capa de mezcla es de 6,85 $\pm 6,49 \mathrm{~m}$. Cabe destacar que en invierno los eventos de surgencia se ven debilitados. Esto debido a que tanto la dirección del viento favorable a la surgencia, como el porcentaje de intensidad requerido 
(a) Componente zonal (octubre 2008)

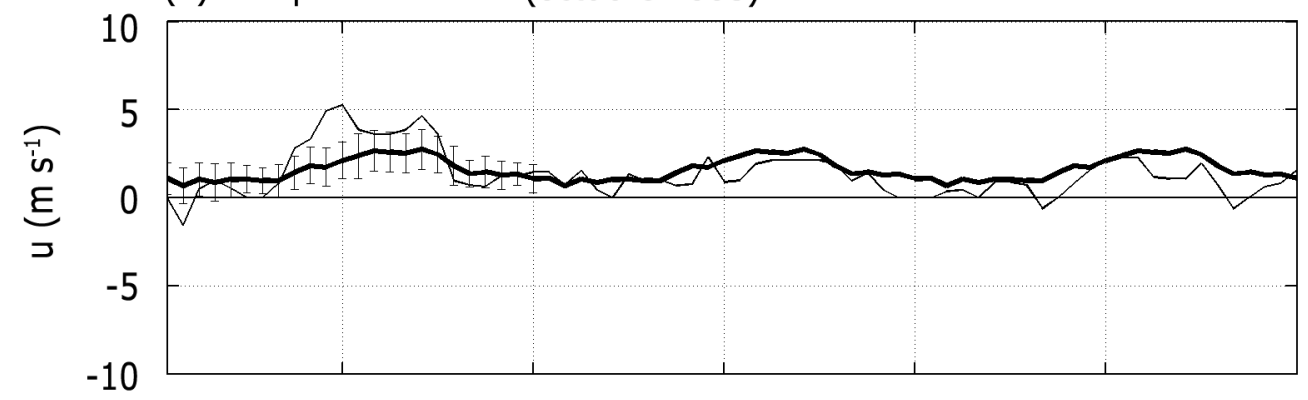

(b) Componente meridional (octubre 2008)

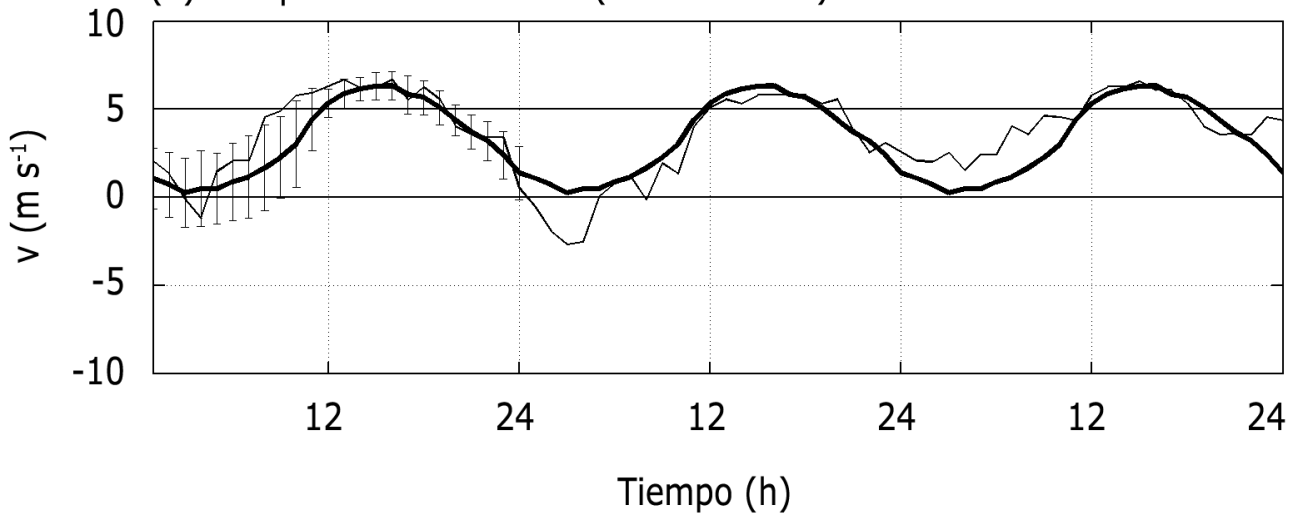

Figura 15. Características del viento para octubre de 2008: (a) Promedio horario mensual de la componente zonal (línea gruesa) con su respectiva desviación estándar y componente zonal horaria para 3 días consecutivos (línea fina), correspondiendo el último día, al de medición (16/10/2008), (b) Promedio horario mensual de la componente meridional con su respectiva desviación estándar horaria (línea gruesa) y componente meridional del viento horaria para 3 días consecutivos (línea fina), correspondiendo el último día, al de medición / Wind characteristics for October 2008: (a) Monthly hour mean zonal component (wide line) and its standard deviation and hourly zonal component for 3 days (thin line), being the last one, the day of observation (16/10/2008). (b) Monthly hour mean meridional component (wide line) and its standard deviation and hourly meridional component for 3 days (thin line), being the last one, the day of observation

para estos procesos se desarrollen se ven disminuidos (Tabla 3 y Tabla 5). A su vez, la presencia de AESS en los niveles superficiales e intermedios al interior de la bahía en el verano extendido (septiembre-abril), pueden atribuirse a los procesos de surgencia que tiene lugar en los focos de surgencia tanto al norte como al sur de la BSJ, tal como queda manifestado en las características del viento propicias para estos eventos (Tabla 3, 4 y 5). Esto se manifiesta concretamente en octubre 2008, donde los vientos favorables a la surgencia para un período de 5 días se generan en un $79,17 \%$, al sumar los porcentajes de la componente $\mathrm{S}$ y SW, y velocidades del viento de la componente zonal mayor e igual a $5 \mathrm{~m} \mathrm{~s}^{-1}$ en un $30 \%$ de las horas promedio diarias para dicho período, observándose un $21 \%$ de porcentaje de AESS en la capa 0 a $10 \mathrm{~m}$ de profundidad y aproximadamente un $65 \%$ en la capa de 30 a $40 \mathrm{~m}$ de profundidad (Fig. 11b). En los niveles por debajo de los $70 \mathrm{~m}$ predomina el AESS en todos las fechas muestreadas (Tabla 1, Figs. 11 y 12). En la capa superficial predomina tanto el ASST como el ASSA, observándose preferentemente el ASST durante la época cálida mientras que el ASSA no muestra un patrón temporal definido en cuanto a su presencia, salvo que sus porcentajes de masa de agua decaen con la profundidad. Dicha masa de agua estaría presente tanto en superficie como en los niveles intermedios.

Evidencias de ASSA, ASST y AESS, han sido identificadas en otros estudios como en la Bahía de Mejillones del Sur (Apablaza \& Palma 2006) con distribuciones verticales de porcentajes de mezcla y distribuciones temporales y en la columna de agua de masas de agua semejantes a este trabajo (Valdés et al. 2006), Sobarzo \& Figueroa (2001) también identifican estas masas de agua frente a la Península de Mejillones, las 
cuales fueron previamente identificadas en zonas oceánicas del norte de Chile (Silva 1983).

El patrón de circulación de las corrientes frente a la BSJ sería uno de los mecanismos responsables de la distribución de las masas de agua, a través del transporte realizado por la Corriente Costera de Chile de dirección reversible frente a la Península de Mejillones (Strub et al. 1998). Dicha corriente sería responsable del ingreso de ASSA y ASST, dado que la zona frente a la Península de Mejillones constituye una zona de transición donde confluyen masas de agua superficiales de origen subtropical y subantártico. Se propone que el ASST ingresaría preferentemente en verano por el lado norte, dado que esta masa de agua se destaca en la época cálida, mientras que el ASSA, sin un patrón temporal definido, ingresaría a la bahía por el lado sur.

La presencia del AESS en las capas superficiales e intermedias, podría atribuirse al mecanismo de surgencia evidenciado tanto en Punta Angamos (Rodríguez et al. 1991), como aquellos registrados al sur de la bahía como Punta Coloso (Escribano \& Hidalgo 2001). Esto permitiría el ascenso de esta masa de agua a la superficie y su posterior ingreso a la bahía, tanto por el extremo norte como por el extremo sur, a través de una corriente costera de dirección variable. Esto se evidencia en los datos de viento de octubre 2008 (Tabla 3), donde la intensidad de la componente meridional puede alcanzar valores adecuados para generar el ascenso de AESS desde mayores profundidades (Sobarzo \& Figueroa 2001) (Fig. 11). Por otro lado las aguas al interior de la BSJ están sujetas a una retención por la circulación ciclónica imperante (Escribano \& Hidalgo 2001), facilitando el incremento de la temperatura, por efecto de la radiación solar, tal como se detecta en la imágenes de TSM de marzo de 2009 (Fig. 13).

Por su parte, Marín et al. (2001) detecta un flujo hacia el sur desde la superficie hasta los $200 \mathrm{~m}$ de profundidad, frente a la Península de Mejillones, aludiendo que se trata básicamente de la Corriente Ecuatorial Subsuperficial (CESS). También postula que esto es factible que ocurra incluso con viento $\mathrm{S}$, de acuerdo a estudios efectuados en sitios con configuraciones similares a esta bahía (Wang 1997). La factibilidad de un flujo costero en dirección al sur también es detectado en la circulación obtenida frente a la Península de Mejillones a través de un estudio numérico de circulación durante el período de invierno (Escribano et al. 2004). Por otra parte, Escribano \& Hidalgo (2001), establecen que entre Punta Tetas y Punta Coloso el flujo neto de las corrientes instantáneas entre la capa superficial hasta los $200 \mathrm{~m}$ es hacia el sur, durante un período de medición de agosto 1999, coincidiendo con la propuesta de Marín et al. (2001). Esto se podría interpretar como efecto del paso de la CESS a nivel subsuperficial y de la CCCh por la capa superficial. A su vez, Escribano \& Hidalgo (2001), proponen un modelo conceptual de circulación de la bahía en base a 3 etapas dinámicas en función de la variabilidad de la intensidad del viento, sin otorgar mayor información de las duraciones de cada una de ellas. La fase inicial comprende un flujo entrante desde el sur inducido por la surgencia costera debido al viento favorable a dicho mecanismo, permitiendo el ingreso de AESS o en su defecto ASSA por el sector sur de la bahía, tal como se sugiere en este estudio.

Otro posible mecanismo de ascenso de AESS a la capa superficial podría deberse al afecto de enfriamiento, típico de la época de invierno (Stewart 2003), dado que la capa de mezcla en esta época del año logra su mayor extensión, promoviendo la mezcla vertical y permitiendo el ascenso de aguas subsuperficiales, tal como se observa en el diagrama T-S del 10 de agosto 2010 (Fig. 9b), coincidiendo con una capa de mezcla extensa (Tabla 2). Sin embargo, al analizar el diagrama de temperatura potencial versus contenido de oxígeno disuelto (Fig. 10b), se observa que desde el punto de vista del contenido del oxígeno disuelto no sólo estaría el AESS sino una masa de agua con similar temperatura pero de mayor contenido de oxígeno entre 2 y $5,5 \mathrm{ml} \mathrm{L}^{-1}$. Este mayor contenido puede atribuirse a procesos de ventilación que sufren las aguas subsuperficiales al entrar en contacto con la superficie.

Escribano et al. (2004) estudiaron la variabilidad del viento de la estación de Cerro Moreno para un período de 17 años (enero 1982 a enero 1999), encontrando que la componente meridional es positiva durante la mayor parte del día con un incremento notorio de 15:00 a 24:00 h, alcanzando valores medios de $4 \mathrm{~m} \mathrm{~s}^{-1}$. Esto concuerda con lo encontrado en este trabajo, dado que en los meses estudiados la componente meridional supera o es igual al valor crítico de $5 \mathrm{~m} \mathrm{~s}^{-1}$ durante el período diurno, cuya extensión horaria en el día depende de la estación del año, al mismo tiempo que el incremento del porcentaje de frecuencias de las componentes S y SW del viento. En efecto, ambas variables se incrementan durante el período de primavera-verano, tal como se hace evidente especialmente en octubre 2008 y en menor medida durante marzo 2009. El viento es de carácter pulsátil diario (Tablas 4 y 5) con ocurrencia diurna presentando variabilidades interdiarias además de estar sujeto a las variaciones estacionales e incluso interanuales, tal como ya ha sido 
observado por Rutland et al. (1998), Escribano \& Hidalgo (2001), y Cantillanez et al. (2005). Por lo tanto, las condiciones propicias para los eventos de surgencia quedan evidenciadas tanto en el porcentaje de velocidad de la componente meridional del viento mayor o igual a 5 $\mathrm{m} \mathrm{s}^{-1} \mathrm{y}$ en intervalo de duración en que dicha velocidad se presenta.

Los resultados de las mediciones hidrográficas y su análisis posterior permiten concluir que:

1. Se evidencia un patrón estacional para la formación de la capa de mezcla y capa estratificada, destacándose el máximo grosor de la capa de mezcla en invierno y el mínimo en verano y de forma contraria para la capa estratificada cuyo comportamiento estacional queda evidenciado a través del parámetro de estratificación, adquiriendo un valor máximo en verano y mínimo en invierno.

2. En la BSJ se identifican modificaciones de 3 masas de agua: ASSA, ASST y AESS. Dichas modificaciones pueden atribuirse a distintos procesos físicos que tienen lugar en la bahía y/o fuera de ella, entre ellos la formación de la capa de mezcla versus capa estratificada, los procesos de surgencia y dinámica de corrientes costeras superficiales y subsuperficiales.

3. La variabilidad temporal de las masas de agua en la superficie puede atribuirse a los procesos de mezcla versus estratificación, que tienen lugar en la capa de 0-20 m aproximadamente, además de los procesos de surgencia costera en los focos característicos como Punta Angamos y Punta Coloso y dinámica de la Corriente Costera de Chile.

4. Los porcentajes de las masas de agua varían en la columna de agua y con las fechas de muestreo. El ASST y ASSA destacan en la capa superficial. El ASST predomina en la época cálida. El ASSA no muestra un patrón temporal definido, estando presente tanto en la superficie como en los niveles intermedios. Su porcentaje de masa de agua es máxima en la superficie y decae con la profundidad. El porcentaje de masa de agua del AESS crece con la profundidad, predominando con porcentajes del orden del $70 \%$ en los niveles de 70-80 m de profundidad.

5. Las variabilidades de los porcentajes de ASSA y ASST dependerían fundamentalmente de las características de la dirección de la corriente costera (Strub et al. 1998) y son modulados por los procesos de surgencia costera responsable de los aportes de AESS a la superficie que tiene lugar preferentemente durante el verano extendido (octubre-abril) y/o por procesos de mezcla en invierno (junio-agosto).

6. El AESS llegaría a la superficie de la BSJ no sólo como consecuencia de los mecanismos de surgencia en los focos característicos y posterior advección por las corrientes costeras sino que también por efecto de enfriamiento, generador de una mezcla vertical, que posibilitaría el ascenso de AESS a la capa intermedia y/o superficial en invierno. En efecto, dicha masa de agua podría estar ingresando tanto de los sectores norte como sur de la bahía proveniente de los focos de surgencia de Punta Angamos y Punta Coloso (entre otros focos), respectivamente.

7. La predominancia de AESS en la capa inferior de la Bahía, observada tanto en los diagramas T_S y porcentaje de mezcla en las fechas de muestreo, indicaría el ingreso de la Corriente Ecuatorial Subsuperficial (CESS) desde el norte y su vaciado por el sur, siendo responsable del transporte de dicha masa de agua.

8. La interacción de las corrientes superficiales y subsuperficiales frente a Península de Mejillones con la variabilidad estacional de la intensidad del viento favorable a la surgencia en los focos de surgencia, además de los procesos de mezcla versus estratificación tendría efecto en la composición y mezcla de las masas de agua en la capa superficial y media, al interior de la BSJ.

\section{Agradecimientos}

Este estudio fue financiado por el Proyecto FNDRCONAMA (JVS) BIP 30059576 Estudio Levantamiento de Información para el Control Ambiental de la Bahía de San Jorge. Se agradece a la Gobernación Marítima de Antofagasta, y Capitanía del Puerto de Antofagasta, por facilitar y disponer de la Lancha Patrullera Costera 'Grumete Díaz' y 'Grumete Salinas', como así también a las diferentes tripulaciones que participaron en cada una de los muestreos. Se agradece en especial la colaboración de Alexis Castillo, Lidia Espinoza, César Calderón, Francisco Lira, Marcos Guiñez, Pedro Flores, Manuel Mancilla, Francisco Maureira y Gonzalo Gómez, quienes participaron en las diferentes campañas oceanográficas. Las datos para el procesamiento de las imágenes satelitales fueron extraídas de la página web <http:// oceancolor.gsfc.nasa.gov>. 


\section{LITERATURA CITADA}

Apablaza P \& S Palma. 2006. Efecto de la zona de mínimo oxígeno sobre la migración vertical de zooplancton gelatinoso en la Bahía de Mejillones. Investigaciones Marinas 34(2): 81- 95.

Barber RT \& RL Smith. 1981. Coastal upwelling ecosystems. In: Longhurst AR (ed). Analysis of marine ecosystems, pp. 31-68. Pergamon Press, New York.

Bourke RH \& JG Pattullo. 1974. Seasonal variations of the water mass along the Oregon-northern California coast. Limnology and Oceanography 19(2): 190-198.

Cantillanez M, M Avendaño, G Thouzeau \& M Le Pennec. 2005. Reproductive cycle of Argopecten purpuratus (Bivalvia: Pectinidae) in La Rinconada marine reserve (Antofagasta, Chile): Reponse to environmental effects of El Niño and La Niña. Aquaculture 246: 181-195.

Emery WJ \& J Meincke. 1986. Global water masses: summary and review. Oceanologica Acta 9: 383-391.

Escribano R \& P Hidalgo. 2001. Circulación inducida por el viento en Bahía de Antofagasta, norte de Chile $\left(23^{\circ} \mathrm{S}\right)$. Revista de Biología Marina y Oceanografía 36(1): 43-60.

Escribano R, VH Marín, P Hidalgo \& G Olivares. 2002. Physical-biological interactions in the pelagic ecosystem of the nearshore zone of the Northern Humboldt Current System. In: Castilla JC \& JL Lagier (eds). The oceanography and ecology of the nearshore and bays in Chile, pp. 145175. Ediciones Universidad Católica de Chile, Santiago.

Escribano R, S Rosales \& JL Blanco. 2004. Understanding upwelling circulation off Antofagasta (Northern Chile): A three-dimensional numerical-modeling approach. Continental Shelf Research 24: 37-53.

Hidalgo-González RM \& S Álvarez-Borrego. 2008. Estructura de la columna de agua y perfiles de biomasa fitoplanctónica en el Golfo de México. Ciencias Marinas 34(2): 197-212.

Kaplan DM, JL Largier, S Navarrete, R Guiñez \& JC Castilla. 2003. Large diurnal temperature fluctuations in the nearshore water column. Estuarine Coastal and Shelf Science 57: 385-398.

Mamayev OI. 1975. Temperature -salinity analysis of world ocean waters. Elsevier Oceanography Series 11: 1-374. Elsevier Scientific Publishing Company, New York.

Marghany M. 2012. Intermonsoon water mass characteristics along coastal waters off Kuala Terengganu, Malaysia. International Journal of Physical Sciences 7(8): 1294-1299.

Marín VH, L Rodríguez, L Vallejo, J Fuenteseca \& E Oyarce. 1993. Efectos de la surgencia costera sobre la productividad primaria primaveral de Bahía Mejillones del Sur (Antofagasta, Chile). Revista Chilena de Historia Natural 66: 479-491.
Marín VH, R Escribano, LE Delgado, G Olivares \& P Hidalgo. 2001. Nearshore circulation in a coastal upwelling site off the Northern Humboldt current system. Continental Shelf Research 21: 1317-1329.

Piñones A, JC Castilla, R Guiñez \& JL Largier. 2007. Temperaturas superficiales en sitios cercanos a la costa en la Bahía de Antofagasta (Chile) y centros de surgencia adyacentes. Ciencias Marinas 33(1): 37-48.

Rodríguez L, V Marín, M Farías \& E Oyarce. 1991. Identification of an upwelling zone by remote sensing and in situ measurements. Mejillones del Sur Bay (AntofagastaChile). Scientia Marina 55(3): 467-473.

Rutland J, H Fuenzalida, R Torres \& D Figueroa. 1998. Interacción océano-atmósfera en la Región de Antofagasta (Chile, $23^{\circ} \mathrm{S}$ ): Experimento DICLIMA. Revista Chilena de Historia Natural 71: 405-427.

Saavedra N \& A Foppiano. 1992. Contribución a la cinemática del anticiclón del Pacífico Sur. Geoacta 19: 95-110.

Silva N. 1983. Masas de agua y circulación en la región norte de Chile Latitudes $18^{\circ} \mathrm{S}-32^{\circ} \mathrm{S}$. (Operación Oceanográfica Marchile XI -Efren II). Ciencia y Tecnología del Mar 7: 47-84.

Simpson JH \& JR Hunter. 1974. Fronts in the Irish Sea. Nature 250: 404-406.

Sobarzo M \& D Figueroa. 2001. The physical structure of a cold filament in a Chilean upwelling zone (Península de Mejillones, Chile, $23^{\circ}$ S). Deep-Sea Research I 48: 26992726.

Stewart RH. 2003. Introduction to physical oceanography, 343 pp. Department of Oceanography, Texas A \& M. University. <http://oceanworld.tamu.edu/resources/ ocng_textbook/PDF_files/book_PDF_files.html>

Strub PT, J Mesías, V Montecinos, J Rutland \& S Salinas. 1998. Coastal ocean circulation off western South America. In: Robinson A \& K Brink (eds). The sea. The Global Coastal Ocean 11: 273-313. Wiley \& Sons, New York.

Tomczak M. 1999. Some historical, theoretical and applied aspects of quantitative water mass analysis. Journal of Marine Research 57: 275-303.

Valdés J, D Román, P Dávila, L Ortlieb \& M Guiñez. 2006. Variabilidad estacional de cadmio en un sistema de surgencia costera del norte de Chile (Bahía Mejillones del Sur, $23^{\circ} \mathrm{S}$ ). Revista Chilena de Historia Natural 79: 517-535.

Wang DP. 1997. Effects of small scale wind on coastal upwelling with applications to Point Conception. Journal of Geophysical Research C 102: 15555-15566. 